\title{
SUBSTITUIÇÃO DE IMPORTAÇÃO NA AGRICULTURA PARAGUAIA O CUSTO DOMÉSTICO DA DIVISA
}

FRANCISCO JOSE SANCHEZ VEGA

Orientador: ZILDA PAES DE BARROS MATTOS

Dissertação apresentada à Escola Superior de Agricultura "Luiz de Queiroz", da Universidade de São Paulo, para obtenção do título de Mestre em Agronomia. Área de Concentração: Economia Agrária.

$P|R A C| C A B A$

Estado de São Paulo - Brasil

Setembro = 1985 
$\bar{A}$ meu pai, Francisco

A minha mae, Blanca

À minha esposa, clavel

$\bar{A}$ minha fitha, iiz.

pelo estímuio constante, 


\section{AGRADECIMENTOS}

Este trabalho não se teria concretizado sem a licença outorgada pelo Diretor da Secretaria Técnica de Planejamento do Paraguai, Dr. Federico Mandelburger e sem a colaboração recebida da Prof $\underline{a}-D^{a} \underline{a}$ Zilda Paes de Barros Mattos, que com o seu estímulo e conhecimento tornou viāvel a idéia desta dissertação.

\section{MENÇAO ESPECIAL MERECEM:}

- o Prof. Dr. Fernandó C. Peres e o Prof.Dr. José F.Noronha, pelas sugestões e criticas, com que procuraram aperfeiçoar este tra balho. .

- Os companheiros de trabalho pelo estimulo oferecido em todo momento.

- Os Professores do Departamento de Economia e Sociologia Rural, que contribuiram para minha formação acadêmica.

- A Sra. Elisa S.Peron pelo excelente trabalho datilogräfico.

A colaboração recebida destas pessoas não as torna coniventes com os eventuais erros contidos no presente trabalho. Elas ajudaram a reduzi-los, daî minha gratidão. 


\section{INDICE}

Pāgina

LISTA DE TABELAS $\ldots \ldots \ldots \ldots \ldots \ldots \ldots \ldots \ldots \ldots \ldots \ldots \ldots \ldots \ldots \ldots \ldots \ldots \ldots \ldots$

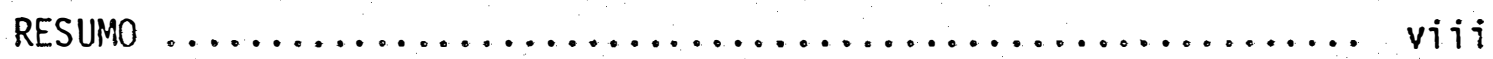

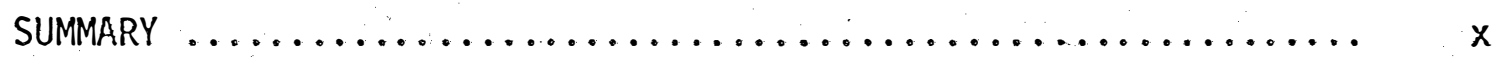

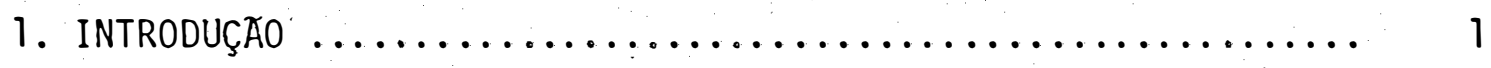

1.1. 0 Problema ............................... 6

1.2. Objetivo Geral ........................... 16

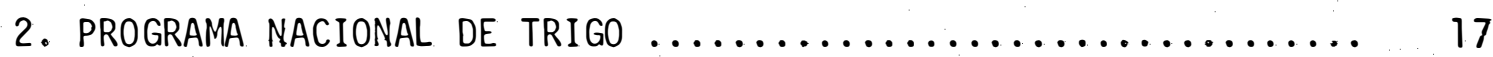

2.1. Apreciação da Política de Produção ............... 17

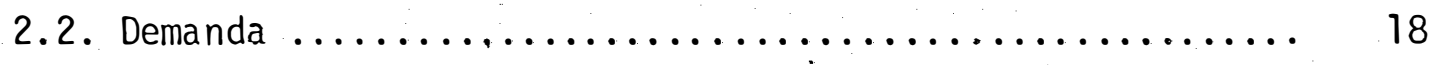

2.3. Oferta ................................ 18

2.3.1. Produção doméstica $\ldots \ldots \ldots \ldots \ldots \ldots \ldots \ldots \ldots . \ldots \ldots$

2.3.2. Importação de trigo ..................... 24

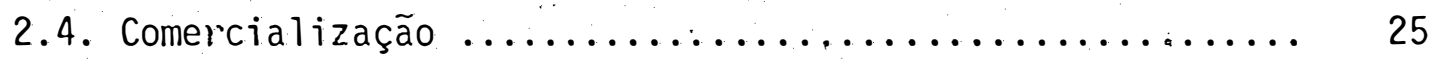

2.4.1. Características gerais ................... 25

2.5. Mercado Doméstico, Evolução do Consumo e Câracte-

rística da Indústria ........................ 25

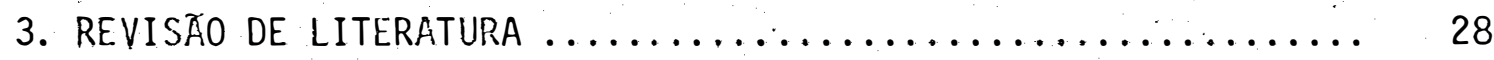

4. METODOLOGIA $\ldots \ldots \ldots \ldots \ldots \ldots \ldots \ldots \ldots \ldots \ldots \ldots \ldots \ldots \ldots \ldots \ldots \ldots \ldots \ldots \ldots, 35$

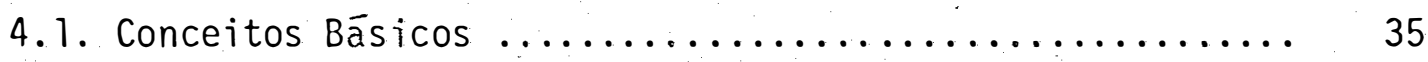

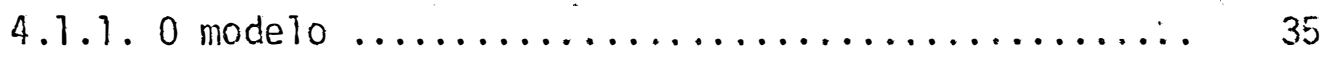

4.1.2. Preço de Conta ...................... 37

4.2. Fornulação Algébrica do Modelo ................. 38 
Pāgina

4.3. Descrição dos Dados Utiiizados .................. 42

4.3.1. Produtos e regiões analisados $\ldots \ldots \ldots \ldots \ldots \ldots . \ldots 4$

4.3.2. Preços ................................. 44

4.3.3. Coeficientes de Produção .................... 51

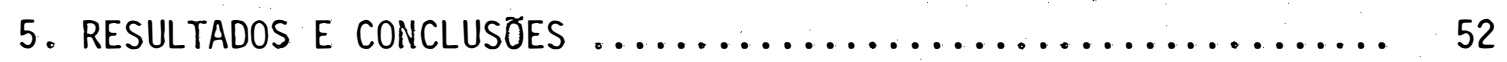

5.1. Estimativa dos Custos Totais e a Taxa de

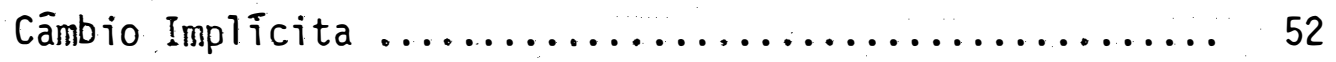

5.2. Resumo e Conclusões $\ldots \ldots \ldots \ldots \ldots \ldots \ldots \ldots \ldots \ldots \ldots \ldots$

5.3. Limitações do Estudo ....................... 59

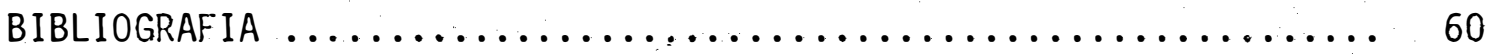

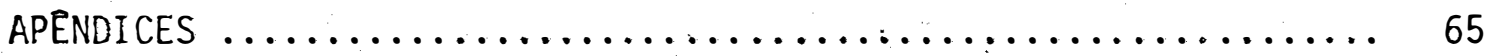




\section{LISTA DE TABELAS}

Tabela no

Pāgina

1 Participação Relativa dos Setores Econômicos no Produto Interno Bruto (PIB) Total, Paraguai, 1972/82 (em mil Gs. constantes de 1977) ............. 2

2 Estrutura e Crescimento da Produção Agropecuāria, Paraguai 1970/82 (Preços de 1977) ............. 4

3 Estrutura e Crescimento das Exportações Agropecuārias, Paraguai, $1965 / 82$................... 5

4 Produção Nacional e Importação de Trigo. Para-

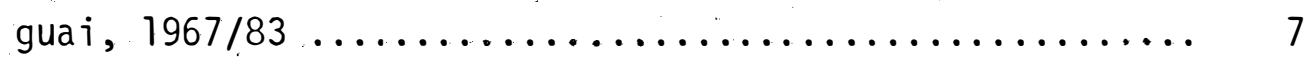

5 Importações de trigo. Paraguai $1967 / 83 \ldots \ldots \ldots \ldots \ldots . .6$

6 Preço Oficial e de Importação dio Trigo, Para-

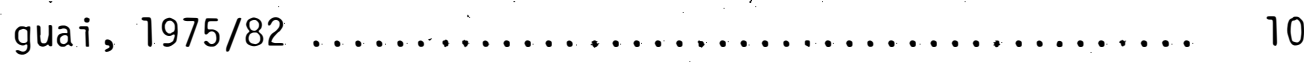

7 Area de plantio total e financiada de trigo, so ja, algodấo e fumo - Paraguai, 1976, 1978, 1980, 1982

8 Balanço de Pagamentos, Paraguai, 1977/82 (mi-

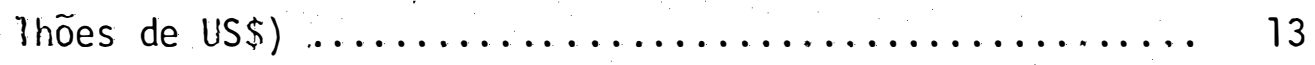

9 Contas Nacionais. Paraguai 1975/82. (Em bilhöes de guaranies de 1977) ....................... 14

10 Indicadores Econômicos Selecionados, Paraguai,

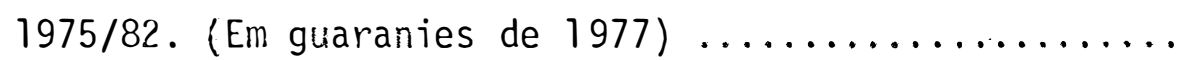


11 Média Anual da Demanda de Trigo, 'Paraguai, $1967 / 82$

12 Area Colhida, Produção e Rendimento do Trigo, Paraguai, $1967 / 83$........................... 20

13 Area Plantada de Trigo nas Principais Regiões Produtoras. Paraguai, 1973, 1977 e 1983 (Em

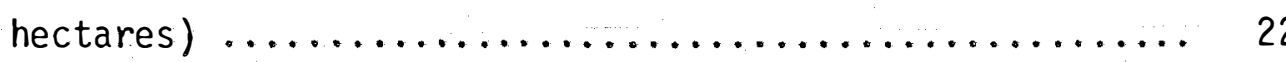

14 Número de Explorações e Area de Plantio do Tri go, Paraguai, 1983

15 Produção, Importação e Consumo de Farinha, Pa-

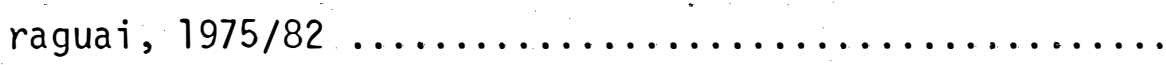

16 Cálculo do Custo Social da Divisa .................. 49

17 Estimativa da Taxa de Câmbio Implícita para Culturas Selecionadas, Paraguai, 1983

18 Quantidade utilizada de mão-de-obra, por hectare, nas culturas de trigo, soja, algodão e fumo, Paraguai, Ano Agricola 1982/83 
viii

\section{SUBSTITUIÇÃO DE IMPORTAÇAO NA AGRICULTURA PARAGUAIA: \\ 0 CUSTO DOMESTICO DA DIVISA}

Francisco José Sanchez Vega Orientador: Zilda Paes de Barros Mattos

RESUMO

0 custo social da polîtica de substituição do trigo importado pelo nacional foi o problema central desse estudo. Dito custo se refere à economia de divisa e alocação eficiente de recursos.

Alêm do trigo foram consideradas três culturas: soja, algodão e fumo, todas com participação significativa nas exportações do Paraguai, a fim de comparar o resultado obtido para estas culturas com 0 trigo. Assim, estimou-se o custo em recursos domésticos envolvidos na produção das quatro culturas mencionadas, como tambēm foi obtido o requerimento de mão-de-obra para cada cultura com a finalidade de conhecer a relação existente entre custo da divisa e a intensidade de utilização des te recurso (considerado abundante no paîs) para cada cultura.

A estimativa do custo foi obtida pelo método do Custo de Recurso Doméstico (CRD) desenvolvido por Michael Bruno o qual permite cal cular o custo de oportunidade aplicado áo fator divisa, em termos do total de recursos domésticos necessários para gerar uma unidade líquida mar ginal de divisa, para ser comparada com a taxa de equilibrio de mercado. 
0 estudo foi feito para o ano de 1983 compreendendo o ano agrî́cola 1982/83. Os resultados indicam que o paîs possui vantagem comparativa na produção da soja, algodão e fumo apresentando dois efeitos positivos: elevação da receira cambial ao lado de uma correta alocação de recursos. o trigo, entretanto, estā em uma situação desfavorável, pois a produção do mesmo gera um custo social para o paîs na magnitude em que a taxa implícita (custo em recurso doméstico) supera a taxa de equilíbrio de mercado.

Por outro lado, o resultado permite afirmar que existe uma relação inversa entre custo e utilização de mão-de-obra ou seja, os produtos que apresentam menores custos na geração de divisa são os que utilizam com maior intensidade este recurso. 


\section{IMPORT SUBSTITUTION IN PARAGUAYAN AGRICULTURE:}

THE DOMESTIC COST OF FOREIGN EXCHANGE

Francisco Josē Sanchez Vega

Adviser: Zilda Paes de Barros Mattos

\section{SUMMARY}

The objective of this study was to estimate the social cost of wheat import substitution policy, in Paraguay.

Three important export crops were also included in the study (soybeans, cotton and tabacco) so that their results could be compared to those obtained for wheat. Thus, production domestic cost for those crops were calculated as well as labor requirement, for each of them, in order to investigate the relationship between cost of foreign exchange and intensity of labor use, an abundant resource in the country.

The cost for each crop was calculated by using Bruno's method of Domestic Cost of Foreign Exchange, which allows the opportunity cost of foreign exchange to be estimated in terms of total domestic resources necessary to generate a net marginal unit of exchange which is compared to the market "equilibrium" exchange rate.

The study was done for 1983, which includes the agricultural year 1982/83. The results indicated that the country has comparative 
advantage on soybeans, cotton and tobacco production whose exports result in gains in foreign exchange in an efficient resource allocation. The wheat crop, however, presented an unfavorable situation since the results showed that its production generates a positive social cost for the country, that is, an implicit rate greater than the market equilibrium exchange rate.

Furthermore, the results showed an inverse relationships between cost and intensity of labor use, that is, the products which presented lower costs of exchange are the ones that utilize labor more intensively. . 


\section{INTRODUÇÃO}

0 desenvolvimento econōmico Paraguaio tem sido influenciado fortemente pela situação geogräfica do paĩs e pela sua dotação de recursos naturais. Limitando-se ao sul com a Argentina, ao norte e a oeste com a Bolívia e a leste com o Brasil, o Paraguai, com seus $406.750 \mathrm{~km}^{2}$, representa pouco mais de $2 \%$ da superfície total da América do Sul e, em termos de tamanho, só excede ao Equador, Guiana, Suriname e Uruguai.

A nação tem acesso indireto ao mar, pelo Rio Paranā ao porto livre de Buenos Aires (aproximadamente a $1.100 \mathrm{~km}$ de Assunção) e por terra em dịreção ao porto livre brasileiro de Paranaguā (aproximada mente a $900 \mathrm{~km}$ de Assunção).

O setor agropecuārio e florestal constitui o de maior im portância econômica e social para o desenvolvimento do paîs, o impulso inicial no a vanço económico do Pâraguai no decênio dos anos setenta originou-se no setor agropecuärio. Por exemplo, no período 1972/82 o setor contribuiu com a terça parte do valor do PIB (Tabela 1); forneceu 
emprego para quase a metade da população economicamente ativa e gerou quase a totalidade das divisas procedentes da exportação, incluindo os produtos agrícolas processados.

Tabela 1. Participação Relativa dos Setores Econōmicos no Produto Interno Bruto (PIB) Total, Paraguai, 1972/82 (em mil Gs. constantes de 1977)

\begin{tabular}{|c|c|c|c|c|c|c|}
\hline \multirow{2}{*}{ Ano } & \multicolumn{4}{|c|}{ Setor Primārio } & \multirow{2}{*}{$\frac{\begin{array}{c}\text { Setor } \\
\text { Secundārio }\end{array}}{\text { Total }}$} & \multirow{2}{*}{$\begin{array}{c}\begin{array}{c}\text { Setor } \\
\text { Terciārio }\end{array} \\
\text { Total }\end{array}$} \\
\hline & Lavoura & Pecuäria & FlorestalI/ & $\overline{\text { Total }}$ & & \\
\hline 1972 & 22.4 & 8.8 & 3.7 & 34.9 & 20.1 & 45.0 \\
\hline 1973 & 22.5 & 8.5 & 3.6 & 34.6 & 20.5 & 44.9 \\
\hline 1974 & 23.1 & 8.4 & 3.6 & 35.1 & 20.5 & 44.4 \\
\hline 1975 & 22.4 & 9.5 & 3.8 & 35.7 & 19.6 & 44.7 \\
\hline 1976 & 22.0 & 9.2 & 3.4 & 34.6 & 19.7 & 45.7 \\
\hline 1977 & 22.5 & 8.2 & 3.4 & 34.1 & 21.3 & 44.7 \\
\hline 1978 & 21.6 & 7.7 & 3.3 & 32.6 & 21.9 & 45.5 \\
\hline 1979 & 20.7 & 7.3 & 3.4 & 31.4 & 22.4 & $46 . ?$ \\
\hline 1980 & 20.6 & 6.8 & 3.4 & 30.8 & 23.3 & 45.9 \\
\hline 1981 & 20.5 & 6.5 & 3.4 & 30.3 & 23.8 & 45.9 \\
\hline 1982 & 20.1 & 6.7 & 3.2 & 30.0 & 23.0 & 47.0 \\
\hline
\end{tabular}

I/ Inclui caça e pesca

FONTE: Cuentas Nacionales, Banco Central del Paraguay, Julio, 1983. 
Durante o dito período, a atividade agropecuária teve um comportamento excepcional. O produto setorial cresceu a uma média anual de $6,8 \%$ entre 1973 e 1976, $11 \%$ em 1977 e em 1978/82 numa média anual de $5,1 \%$ (Tabela 2).

Este crescimento viu-se estimulado pelas boas condições da demanda externa, provavelmente pelo uso mais difundido e eficiente de maquinária agrícola e de insumos modernos, assim como pelo término de vārios investimentos pūblicos em grande escala que melhoraram a infraestrutura, especialmente das estradas e dos silos.

No tocante ao comércio externo, depois de cinco anos de um relativo estancamento que teve lugar no periodo de 1965 a 1970, o aumento dos preços internacionais incentivou o crescimento das exportações agropecuárias que alcançou no perīodo 1971-75 um crescimento médio anual de $25,1 \%$, diminuindo novamente no período $1976-82$ para $11,7 \%$ (Tabela 3).

A crescente abertura da economia vem se manifestando cla ramente pelo crescimento do comércio como os paîses vizinhos Argentina e Brasil, cuja participação conjunta no comércio exterior do Paraguai passou de $11 \%$ do total em 1960 a $40 \%$ ao final da década passada. Portanto, as perspectivas do desenvolvimento paraguaio estão progressivamente condicionados a situação econômica de seus vizinhos. Isto é verdade não somente pelas interrelações comerciais como também pelos crescentes laços económicos que resultam da participação conjunta desses 


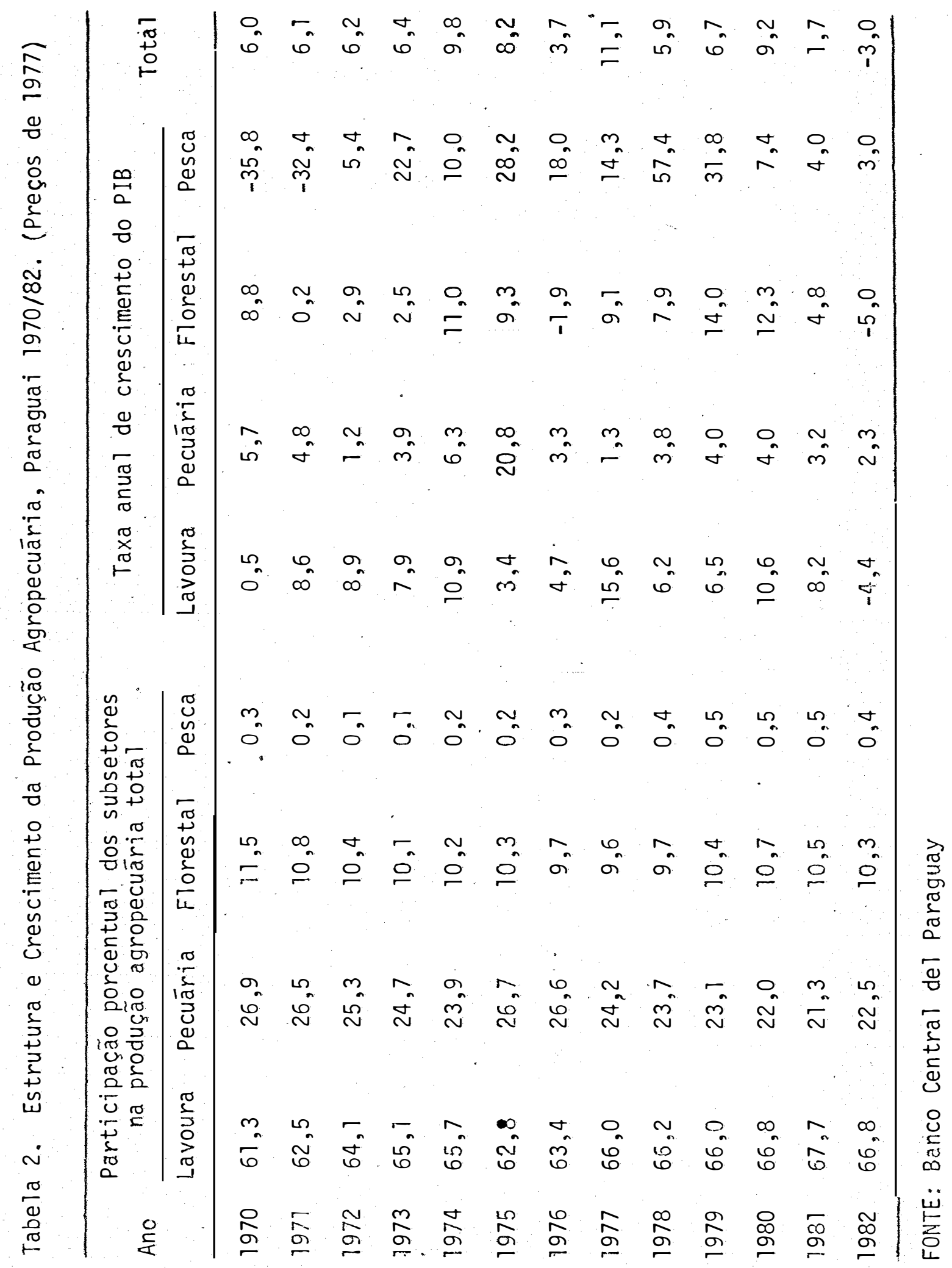


países nos projetos hidroelétricos de Itaipu e Yacyreta?', e os efeitos secundārios destes sobre o turismo, empregö, comércio e outras atividades econômicas.

Tabela 3. Estrutura e Crescimento das Exportações Agropecuārias, Paraguai, $1965 / 82$

\begin{tabular}{|c|c|c|c|c|c|c|}
\hline & \multicolumn{3}{|c|}{$\begin{array}{l}\text { Taxa anual mēdia de } \\
\text { crescimentoal } \\
\text { (em } \%)\end{array}$} & \multicolumn{3}{|c|}{$\begin{array}{l}\text { Participação } \\
\text { Percentual } \\
\text { do setor }\end{array}$} \\
\hline & $1966-70$ & $1971-75$ & $1976-82$ & 1965 & 1970 & 1982 \\
\hline Total de exportações & 2.2 & 23.8 & 10.7 & 100.0 & 100.0 & 100.0 \\
\hline Setor agropecuārio의 & 1.6 & 25.1 & 11.7 & 96.8 & 98.8 & 98.8 \\
\hline Lavoura- & 1.8 & 33.9 & 27.5 & 59.9 & 53.8 & 82.9 \\
\hline - Al godão & - & 37.8 & 35.9 & 8.2 & 6.2 & 37.1 \\
\hline - Soja & - & $106.5^{\mathrm{Cl}}$ & 40.9 & - & $1.4^{C /}$ & 27.1 \\
\hline - Fumo & - & 15.8 & -7.2 & 7.5 & 9.0 & 1.8 \\
\hline - Outras & - & 17.0 & 10.0 & 44.2 & 55.2 & 16.9 \\
\hline Produtos Pecuārios & -1.3 & 17.9 & -5.6 & 32.7 & 17.6 & 2.7 \\
\hline Florestal & 7.8 & 24.6 & 21.3 & 4.2 & 9.4 & 13.2 \\
\hline
\end{tabular}

a/ Obtido a partir de valores FOB em mil dólares correntes

b/ Inclui alguns produtos elaborados

c/ As exportações de soja se referem aos períodos 1972-75

FONTE: Banco Central del Paraguay. Boletim Estatístico nọ 301, 1983.

I/ Hidroelétrica a construir-se sobre o rio Paranā junto com a Argentina. 
A tendência da abertura da economia também tem sido reforçada pela larga tradição governamental de políticas econômicas de "laissez-faire". Entre outras manifestações, essa tradição se revela pela virtual ausência de controle de preços, pela rāpida absorção dentro da economia doméstica de mudanças nos preços externos e por um setor público de pequenas proporções, cujọ impacto sobre os nîveis de ati vidades econômicas é pequeno em comparação à maioria das nações latinoamericanas .

Pode-se afirmar ássim, que o Paraguai estā centrado nas’ bases para um desenvolvimento econōmico de acordo com sua evidente vantagem comparativa na produção do setor primário.

1.1. 0 Problema

Como se observa na Tabela 3, o Paraguai pode ser caracte rizado como um paîs seguidor do modelo primário exportadior. Assim, produtos primārios são trocados por produtos manufaturados no mercado internacional. o único produto agrícola importante que o paîs não produz de modo a satisfazer a demanda doméstica, é o trigo.

No passado, a participação do trigo importado no consumo nacional chegou a assumir grandes proporções. Em 1967, por exemplo, essa participipação chegou a representar praticamente $90 \%$ do consumo total (Tabela 4). 0 valor das importações de trigo no total de importações do paîs, chegou a atingir tambēm proporções razoáveis. Em 1968, por exemplo, esse valor foi de $9,3 \%$ (Tabela 5 ). Esta situação tornava o 
Tabela 4. Produçăo Nacional e Importação de Trigo. Paraguai, 1967/83

\begin{tabular}{|c|c|c|c|c|}
\hline $\begin{array}{l}\text { Ano } \\
\text { (1) }\end{array}$ & $\begin{array}{c}\text { Produção } \\
\text { Nacionala/ } \\
(t) \\
(2)\end{array}$ & $\begin{array}{c}\text { Importação- } \\
(t) \\
(3)\end{array}$ & $\begin{array}{l}\text { Oferta } \\
\text { rotal } \\
(t) \\
(4)\end{array}$ & $\begin{array}{c}\text { Participação do } \\
\text { trigo importado } \\
(\%) \\
(3) /(4)\end{array}$ \\
\hline 1967 & 9.100 & 80.299 & 89.399 & 89,8 \\
\hline 1968 & 20.100 & 89.834 & 101.739 & 81,1 \\
\hline 1969 & 31.400 & 65.482 & 99.782 & 65,6 \\
\hline 1970 & 47.700 & 71.029 & 118.729 & 60,0 \\
\hline 1971 & 54.800 & 60.850 & 115.650 & 52,6 \\
\hline 1972 & 17.600 & 53.709 & 71.309 & 75,3 \\
\hline 1973 & 23.000 & 12.515 & 35.515 & 35,2 \\
\hline 1974 & 35.000 & 45.233 & 80.233 & 55,4 \\
\hline 1975 & 20.800 & 16.336 & 37.136 & 43,9 \\
\hline 1976 & 32.300 & 30.964 & 63.264 & 48,9 \\
\hline 1977 & 28.300 & 43.695 & 79.995 & 60,6 \\
\hline 1978 & 38.000 & 48.749 & 86.749 & 56,2 \\
\hline 1979 & 59.000 & 64.458 & 123.458 & 52,2 \\
\hline 1980 & 46.000 & 74.597 & 120.591 & 67,7 \\
\hline 1981 & 54.000 & 67.720 & 121.720 & 55,6 \\
\hline 1982 & 65.000 & .37 .512 & 102.512 & 36,5 \\
\hline 1983 & 80.000 & 92.866 & 172.866 & 53,7 \\
\hline
\end{tabular}

FONTE: a / Ministërio da Agricultura y Ganaderia, Paraguai, 1984

b/ Secretaria Técnica de Planificación Divisiōn, Comércio Exterior, Paraguai, 1984. 
Tabela 5. Importações de trigo. Paraguai 1967/83

\begin{tabular}{|c|c|c|c|c|c|}
\hline $\begin{array}{l}\text { Ano } \\
(1)\end{array}$ & $\begin{array}{c}\text { Volume } \\
(t) \\
(2)\end{array}$ & $\begin{array}{c}\text { Preço } \\
\text { Médio } \\
\text { (FOB US\$) } \\
(3)\end{array}$ & $\begin{array}{c}\text { Cus to } \\
\text { Total } \\
\text { FOB } \\
\text { (milhões } \\
\text { US\$) } \\
(4)\end{array}$ & $\begin{array}{l}\text { Valor Total } \\
\text { FOB das im- } \\
\text { portações } \\
\text { (milhões US\$) } \\
\text { (5) }\end{array}$ & $\begin{array}{l}\text { Participação da } \\
\text { Importação do } \\
\text { Trigo no Total } \\
\text { das Importações } \\
(4) /(5) \cdot 100\end{array}$ \\
\hline 1967 & 80.299 & 63.04 & 5,063 & 60,654 & 8,3 \\
\hline 1968 & 89.839 & 63.83 & 5,735 & 61,495 & 9,3 \\
\hline 1969 & 65.482 & 66.99 & 4,387 & 70,428 & 6,1 \\
\hline 1970 & 71.029 & 58.93 & 4,186 & 63,834 & 6,5 \\
\hline 1971 & 60.850 & 58.55 & 3,563 & 70,272 & 5,0 \\
\hline 1972 & 53.709 & 63.11 & 3,390 & 69,849 & 4,8 \\
\hline 1973 & 12.515 & 76.86 & 0,962 & 104,790 & 0,9 \\
\hline 1974 & 45.233 & 157.00 & 7,102 & 171,396 & 4,1 \\
\hline 1975 & 16.336 & 181.07 & 2,958 & $\therefore \quad 178,361$ & 1,6 \\
\hline 1976 & 30.964 & .169 .93 & 5,262 & 180,218 & 2,9 \\
\hline 1977 & 43.695 & $=124.88$ & 5,457 & 255,376 & $2, i$ \\
\hline 1978 & 48.749 & 99.70 & 4,863 & 317,737 & 7,5 \\
\hline 1979 & 64.458 & 127.15 & 8,196 & 437,721 & 1,8 \\
\hline 1980 & 74.591 & 158.67 & 11,836 & 517,141 & 2,2 \\
\hline 1981 & 67.720 & 203.23 & 13,763 & 506,110 & 2,7 \\
\hline 1982 & 37.512 & 181.11 & 6,794 & 581,474 & 1,1 \\
\hline 1983 & 92.866 & 166.90 & 15,499 & 478,264 & 0,3 \\
\hline
\end{tabular}

FONTE: Secretaria Técnica de Planificaciōn. Divisiōn Comércio Exterior, Paraguay, 1984. 
Paraguai altamente dependente da Argentina, principal exportador de trigo (no ano de 1966 responsável por 95\% do trigo importado no país) que exercia antigamente fortes influencias sobre a estabilidade do governo do Paraguai. Este foi o principal notivo que levou o governo a adotar uma politica de substituição de importação de trigo, embora isto resultasse, obviamente, tambēm em econoṇia de divisas para o paîs.

A política de substituição de importação foi adotada em 1965 e implementada em 1967 atravēs do Programa Nacional de Produção de Trigo, com a finalidade de aumentar de forma contínua a produção destá cultura e diminuir as importaçöes anuais do paîs. Antes de ser adotada a política de substituição do trigo importado pelo trigo nacional, este produto nunca teve planos a longo prazo. Os estímulos para o iricremento da produção tritícola nacional estiveram apoiados até hoje em duas políticas: uma de preços mínimos e outra creditîcia, através do incremento do volume de crédito destinado para o cultivo deste cereal. Assim, pode-se observar na Tabela 6 , que os preços domésticos (Preços mĩnimos) sempre ficaram acima do preço CIF de importação, chegando a atingir no ano de 1982 um valọ de 38\% acima daquele preço.

Apesar da diferença entre o preço doméstico e o preço CIF de importação, o consumidor (moinho) tem pago sempre o maior preço, uma vez que o trigo importado é adquirido atravēs de uma comissão de compra e vendido aos moinhos ao mesmo preço do trigo nacional. Além disso, o crédito, que também se constitui num estímulo ao programa, dei xa esta cultura numa posição privilegiada com respeito a outros produtos importantes como a soja, aigodão e fumo. Da ärea total de plantio 
de trigo, mais de $60 \%$ foi financiado (Tabela 7). Além disso, a taxa de juro cobrada pelo Banco de Fomento ao Sétor Agrícola é de 18\% ao ano, enquanto do setor comercial é cobrada uma taxa de juro ao redor de $30 \%$ ao ano. Em termos reais, a taxa de juro para o setor agrícola é muito baixa jă que nos ūltimos cinco anos a inflação anual tem estado ao redor de $14 \%$, o que resulta numa taxa de juro real de somente $3,5 \%$, enquanto para o setor comercial essa taxa é de $14 \%$ ao ano.

Tabela 6. Preço Oficial e de Importação do Trigo, Paraguai, 1975/82

\begin{tabular}{lcc}
\hline Ano & $\begin{array}{c}\text { Preço oficial } \\
g_{\mathrm{S}} / \mathrm{kg}\end{array}$ & $\begin{array}{c}\text { Preço CIF]/ } \\
\text { importação } \\
g_{\mathrm{S}} / \mathrm{kg}\end{array}$ \\
\hline 1975 & 27 & 22,8 \\
1976 & 25 & 23,2 \\
1977 & 25 & 17,0 \\
1978 & 22 & 13,6 \\
1979 & 22 & 17,1 \\
1980 & 26 & 20,0 \\
1981 & 28 & 26,5 \\
1982 & 33 & 23,8 \\
\hline
\end{tabular}

1/ Transformado em guaranis pela taxa de câmbio oficial FONTE: Secretaria Técnica de Planificaciōn, Paraguai, 1983. 


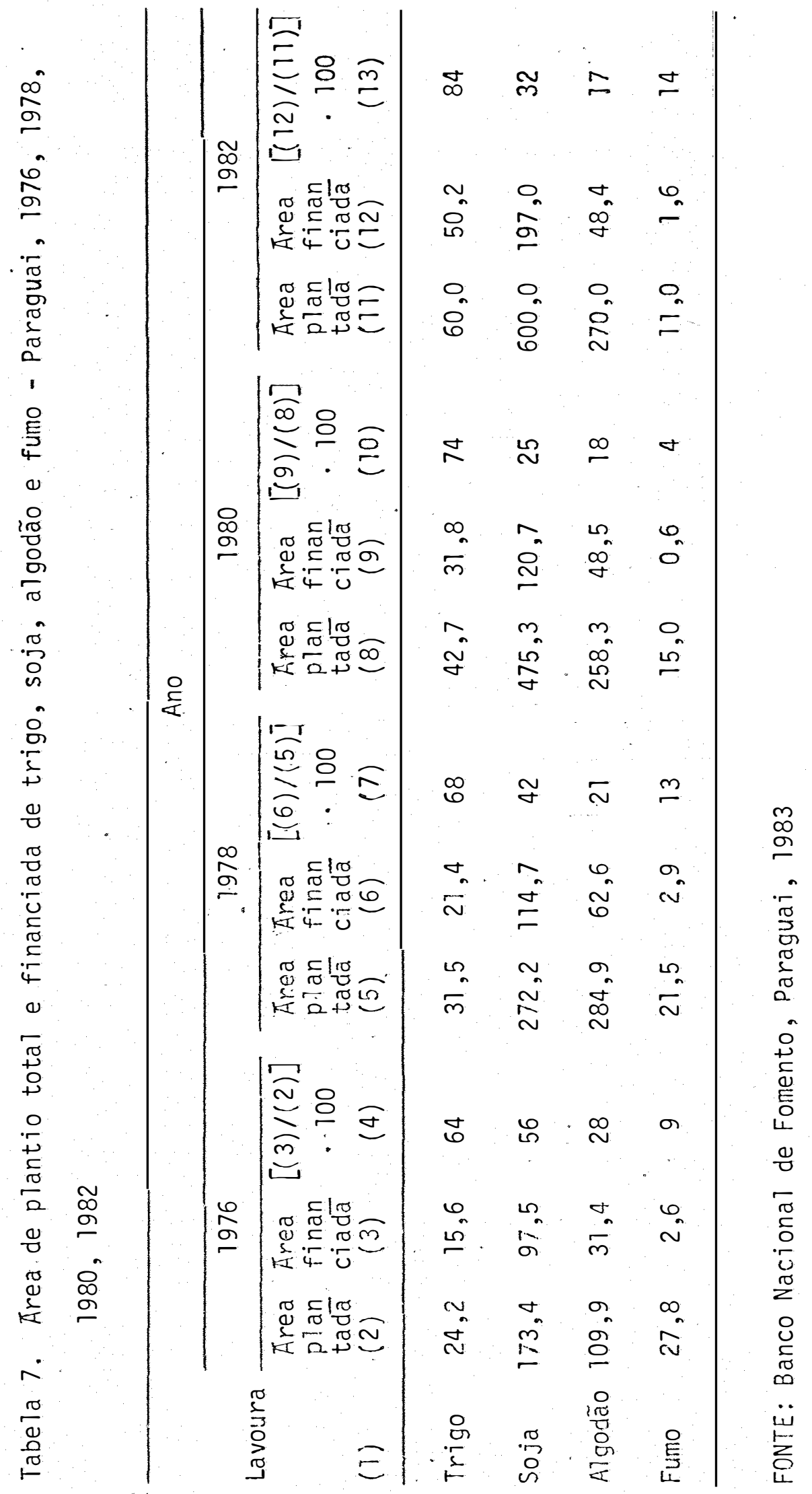


Nos ūltimos anos, entretanto, o programa de substituição do trigo importado ganha maior importăncia no seu aspecto econômico do que no seu início, jā que desde 1982 quebra-se a tendência expansiva da economia, que havia começado uma década antes. Em 1980, os pre ços de exportação dos produtos mais importantes para o comércio exterior do Paraguai experimentou uma queda, ao mesmo tempo em que começa a sobrevalorização cambial. A diminuição na receita se traduz em uma queda de $15 \%$ na ārea cultivada com soja e de $20 \%$ na área com algodão. No ano seguinte, a queda nos preços reais e grandes enchentes, voltam a afetar a produção agrî́cola que diminui em 4,5\% em 1982 e 6,4\% em 1983.

Em 1981 se reduz significativamente o efeito dinâmico da construção de Itaipu, assim como também ocorre a mudança na economia argentina que ocasiona a suspensão dos trabalhos da construção de Yacyreta.

As perdas na receita externa, se traduzem em um crescente deficit nas transações correntes do balanço de pagamento que alcânça a cifra de 1.136,2 milhões de dōlares em 1981 (Tabela 8). Nesse ano, a taxa no mercado negro que se manteve estável (140 guaranies por dólar) por mais de 20 anos, sofre um incremento de mais de 100\% depois de ter ficado no māximo 10\% acima do câmbio oficiàl (126 guaranies por dólar). Em julho de 1982 o Banco Central aprova uma nova taxa cie câmbio oficial (160 guaranies por dōlar) dando origem a uma taxa múltipla de câmbio para os diversos produtos de exportação e importação, onde ao trigo correspondia a menor taxa. 
Tabela 8. Balanço de Pagamentos, Paraguaj, 1977/82. (mi lhões de US $\$$ )

\begin{tabular}{lrrrrr}
\hline & 1978 & 1979 & 1980 & 1981 & 1982 \\
\hline Bàlanço Comercial & $-566,1$ & $-749,0$ & $-652,6$ & $-1055,6$ & $-1123,6$ \\
Transações Correntes & $-706,5$ & $-959,6$ & $-895,3$ & $-1136,2$ & $-1661,6$ \\
Saldo do Balanço de Pagamentos & 168,7 & 168,5 & 161,8 & 53,2 & $-70,4$ \\
\hline
\end{tabular}

FONTE: Elaborado com dados do Banco Mundial, Paraguai, 1984

As finanças püblicas também sentem a perda agregada de receita da economia, gerando-se déficit e ampliações do crēdito püblico, que também favorece a inflação. As condições de instabilidade dificultam a manutenção dos níveis de investimento doméstico. Aumenta o desemprego, diminuem as receitas, o consunio e o investimento, ao mesmo tempo em que o balanço de transações correntes apresenta déficit crescente (Tabelas 8,9 e 10).

A maioria dos fatores das crises sao conjunturais e o paîs absorve seus efeitos sem apresentar conflitos sociais e politicos.

Diante desta situação o programa de produção do trigo ną cional, apresenta maior força, dados os benefícios que pode trazer para a economia do paîs, tais como poupar divisas e a mesmo tempo criar alternativa para melhor utilização dos recursos, terra e mão-de-obra, ou seja, o trigo é produzido no período de inverno, onde as tarefas agrícolas, pela falta de outros produtos, são bastante reduzidas. 


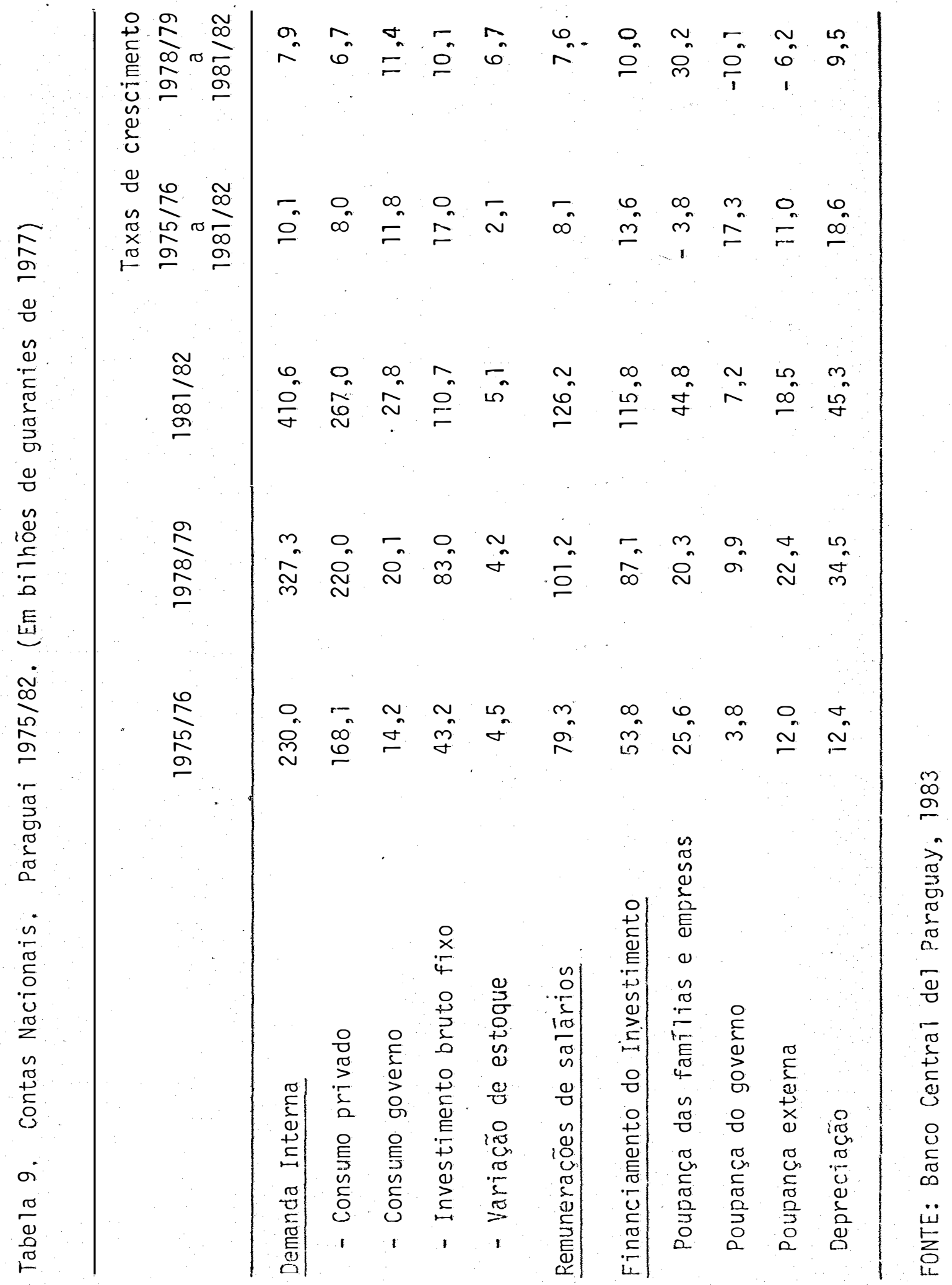


Tabela 10. Indicadores Econōmicos Selecionados, Paraguai, 1975/82. (Em guaranies de 1977)

\begin{tabular}{lccc}
\hline & $1975 / 76$ & $1978 / 79$ & $1981 / 82$ \\
\hline $\begin{array}{l}\text { Taxa anual de crescimento do } \\
\text { investimento bruto }\end{array}$ & 14,5 & 20,9 & $-1,4$ \\
$\begin{array}{l}\text { Coeficiente de Investimento: PIB } \\
\begin{array}{l}\text { Participação da poupança externa } \\
\text { no investimento (\%) }\end{array}\end{array}$ & 2,1 & 28,3 & 29,9 \\
$\begin{array}{l}\text { Indice de preços implícitos no, } \\
\text { PIB (taxa anual) }\end{array}$ & 22,3 & 25,7 & 16,0 \\
$\begin{array}{l}\text { Indice de preços agrícolas } \\
\text { Indice de preços industriais }\end{array}$ & 14,0 & 12,0 & 4,6 \\
Indice de salários. & 8,8 & 14,1 & 13,2 \\
\end{tabular}

FONTE: Banco Central del Paraguay, 1983.

Apesar dos potenciais beneficios que tal programa possa trazer à nação, não se pode esquecer que associados a eles existem cus:tos. No Paraguai, entretanto, não existem estudos empíricos que procurem estimar o custo que representa para'o país a adoção da politica de substituição do trigo importado. 0 que gera?mente existe é a quantificação dos benefícios. Mas calcular os benefícios sem ter em conta os custos é um erro muitas vezes cometido. Assim, o presente trabalho pretende quantificar esse custo para que o mesmo possa fazer uma avaliação da politica de substituiçăo da importação do trigo. 
Ainda que a produção tritîcola também reuna aspectos não econômicos, a avaliação econômica se justifica uma vez que a adoção de uma politica desse tipo resulta em benefícios e custos sociais.

\subsection{Objetivo Geral.}

0 objetivo geral deste trabalho ē avaliar a politica de substituição de importação do trigo no Paraguai no que se refere a economia de divisa e alocação eficiente de recursos. Os objetivos especĩficos săo:

1. Calcular o custo, em recursos domésticos, para gerar um dôlar poupado atravēs da produção do trigo via substituição de importaçäo e compará-10 com o custo de oportunidade cia divisa dos princi-pais produtos de exportaçāo.

2. Ordenados os custos da divisa para os diferentes pro.dutos, estimar o requerimento de mão-de-obráa parà os mesmos, na tentativa de saber se os produtos que apresentám um menor custo por divisa gerada, são us que mais absorvem mão-de-obra, o fator supostamente mais abundante no pais. 
2. PROGRAMA NACIONAL DE TRIGO

\subsection{Apreciação da Polittica de Produção}

Como foi dito no Cápitulo 1, Introdução, o programa de produção do trigo foi implementado no ano de 1967 e o argumento mais importante para sua adoção foi político, embora também isso resultasse em economia de divisa. Mas, a decisão de produzir internamente visando autosuficiência, pressupõe um incremento no preço do trigo, de modo que à taxa de lucro seja atraente para sua produção, podendo criar com isso um custo social, cuja magnitude não se conhece. Por outro lado, tâmbém é possîvel que a longo prazo, como resultado de economia de escala ou do progresso tecnológico (especialmente tecnologia biológica), o custo de produção possa diminuir, trazendo com isso uma diminuição no custo social. 
2.2. Demanda

A demanda domẹstica do trigo é composta de duas partes: consumo e sementes.

Como se pode observar, durante o período 1967/82 o principal componente da demanda foi o consumo, que participou com $93,5 \%$ do total demandado.

Tabela 11. Média Anual da Demanda de Trigo, Paraguai, 1967/82

\begin{tabular}{lrc}
\hline $\begin{array}{l}\text { Componentes } \\
\text { da demanda }\end{array}$ & $\begin{array}{c}\text { Quantidáde média } \\
\text { anual demandada } \\
(t)\end{array}$ & $\begin{array}{c}\text { Participação } \\
\text { percentual } \\
(\%)\end{array}$ \\
\hline Consumo & $94.448,6$ & 93,5 \\
Semente & $3.560,4$ & 3,5 \\
Perdida & $2.953,5$ & 3,0 \\
Total & $100.962,5$ & 100,0 \\
\hline
\end{tabular}

FONTE: Recopilaciōn de Trabajos Presentados para la elaboraciōn del Pro grama Nacional de Trigo. STP, Paraguai, 1983

\section{3. $\underline{\text { Oferta }}$}

A oferta de trigo no Paraguai é composta pela produção doméstica e pelas importações, como foi exposto na primeira parte do tra balho. 


\subsubsection{Produção domēstica}

o trigo é uma cultura conhecida no paîs há muito tempo. Ao redor do ano de 1900, foram feitos os primeiros trabalhos experimentais em Assunção e outros lugares, mas a cultura não teve continuidade na sua produção devido principalmente ao abandono dos serviços experimentais, já que periodicamente deveŕ-se-ia dispor de novas variedades que substituirian as existentes, na medida em que novas doenças se manifestassem.

Em 1943 são novamente realizados trabalhos de pesquisa com a introdução de variedades procedentes de Campinas (Brasil), mas sem ter ainda os recursos técnicos e financeiros necessários.

Finalmente, em 1965, o governo assume a responsabilidade de fomentar a produção do trigo nacional de forma planejada, atravēs da criação do Programa Nacional, implementado em 1967.

De 1967 a 1971 a área colhida teve um incremento significativo. A partir do ano de 1971, há uma queda (de curta duração) devicio ao aparecimento de pragas e doenças que estragaram os cultivos e diminuiram a percentagem de recuperação dos crēditos e consequentemente ocasionaram uma diminuição nos saldos disponíveis dos mesmos, para os anos posteriores.

De 1973 em diante existiu uma série de mudanças, mas a tendência foi de aumento na área colhida, chegando no ano de 1983 a 75 mil hectares, 254\% a mais da área colhidà nos três primeiros anos. 
Tabela 12. Area Colhida, Produção e Rendimento do Trigo, Paraguai, 1967/ 83

\begin{tabular}{lccc}
\hline Ano & $\begin{array}{c}\text { Area colhida } \\
\text { (mil hectares) }\end{array}$ & $\begin{array}{c}\text { Produção } \\
(\text { mi } t)\end{array}$ & $\begin{array}{c}\text { Rendimento } \\
\text { (kg/hectare) }\end{array}$ \\
\hline 1967 & 8,3 & 9,1 & 1.100 \\
1968 & 20,9 & 25,1 & 1.200 \\
1969 & 34,3 & 31,4 & 915 \\
1970 & 44,7 & 47,7 & 1.065 \\
1971 & 51,5 & 54,8 & 1.064 \\
1972 & 32,0 & 17,6 & 550 \\
1973 & 20,3 & 23,0 & 1.133 \\
1974 & 32,1 & 35,2 & 1.097 \\
1975 & 23,4 & 20,8 & 889 \\
1976 & 24,2 & 29,3 & 1.209 \\
1977 & 28,5 & 28,3 & 992 \\
1978 & 31,5 & 37,8 & 1.203 \\
1979 & 55,0 & 59,0 & 1.072 \\
1980 & 42,7 & 46,0 & 1.077 \\
1981 & 48,3 & 54,0 & 1.118 \\
1982 & 60,0 & 65,0 & 1.080 \\
1983 & 75,0 & 80,0 & 1.066 \\
\hline
\end{tabular}

FONTE: Departamento de Censo y Estadisticas Agropecuarias, Ministério de Agricultura y Ganaderia, Paraguai, 1984 
A evolução da produção acompanhou de perto a evolução da ārea colhida, de forma que à produtividade (produção por hectare) pouco variou, ficando a média para o período de 1967/83 em torno de $1.048 \mathrm{~kg} /$ hectare 2 . Esse valor è ainda baixo se o comparamos com valores de produtividades de outros países como os EE. UU. $12.321 \mathrm{~kg} / \mathrm{hecta-}$ re) ou México $(3.700 \mathrm{~kg} /$ hectare $)$.

\subsubsection{Regiões de Produção}

As características ecológicas, o tipo de exploração e os resultados das pésquisas têm determinado as principais regiões de produção do paîs. A principal delas é Itapua (Tabela 13), responsável no ano de 1983 por $71 \%$ da área plantada do trigo.

Em segundo lugar estā o Alto Paranā que sō nos ūitimos anos tem evoluído bastante representando $14 \%$ do total, e em terceiro lu gar estā o departamento ${ }^{3}$ / de San Pedro que teve uma participação de $9 \%$. As três regiões são responsáveis por $94 \%$ da ārea plantada de trigo no paîs.

2/ Se considerāssemos a ārea plantada, provavelmence a variação da produtividade seria maior.

3/ Corresponde a um estado federativo do Brasil. 
Tabela 13. Area Plantada de Trigo nas Principais Regiões Produtoras. Paraguai, 1973, 1977 e 1983. (Em hectares)

\begin{tabular}{lrrr}
\hline \multirow{2}{*}{ Departamento } & \multicolumn{3}{c}{ Ano } \\
\cline { 2 - 4 } & \multicolumn{1}{c}{1973} & \multicolumn{1}{c}{1977} & 1983 \\
\hline San Pedro & 4.100 & 8.600 & 6.832 \\
Caaguazu & 100 & 2.800 & 2.250 \\
Itapua & 9.200 & 13.500 & 53.219 \\
Misiones & 3.600 & 3.000 & 670 \\
Alto Paranā & 500 & 500 & 10.400 \\
Conendiyu & - & 1.300 & 70 \\
Outros & 6.100 & 3.100 & 1.580 \\
Total & & 32.800 & 75.021 \\
\hline
\end{tabular}

FONTE: Direciōn de Investigaciōn y Extensiōn Agropecuāria, MAG, 1984.

2.3.1.2. Número de produtores e äreas plantadas

A maior parte da área plantada (68\%) se encontra em mầos de produtores com mais de 50 hectares, os quais, segundo a classificação do Banco Nacional de Fomento, são considerados mêdios e grandes pro dutores (Tabela 14). 
Tabela 14. Nümero de Explorações e Area de Plantio do Trigo, Paraguai, 1983

\begin{tabular}{lccc}
\hline $\begin{array}{c}\text { Estrato de tamanho da } \\
\text { propriedade (ha) }\end{array}$ & $\begin{array}{c}\text { Nümero de } \\
\text { produtores }\end{array}$ & $\begin{array}{l}\text { Area plan- } \\
\text { tada (ha) }\end{array}$ & $\%$ \\
\hline$<50$ & 1.165 & 24.006 & 32 \\
50 a 200 & 184 & 15.004 & 20 \\
$>200$ & 42 & 36.011 & 48 \\
Total & 1.391 & 75.021 & 100 \\
\hline
\end{tabular}

2.3.1.3. Fatores limitantes da produção

Tem sido apontado como um dos principais fatores que interferem negativamente na expanșão da produção do trigc, a baixa margem de lucro, a qual não compensa o risco económico que representa para o produtor essa cultura, ainda mais nos anos críticos, devido principalmente a: a) falta de variedades com alto potencial de produção e resistentes, já que existe um complexo de doenças que afetam o rendimen to, atualmente e b) o número reduzido de produtores que consegue aplicar o conjunto de práticas.agronômicas recomendadas pará o plantio, devido provavelmente ao limitado alcande do serviço de assistência técnica e também à insuficiente capacidade financeira do produtor para a compra dos insumos necessários para a produção, na maioria importados. 
Mesmo que existam fatores limitantes argumenta-se que a produção de trigo poderia ser incrementada. se se considerar a complementariedade que o mesmo tem com a soja,

Existem evidências empîricas de que o trigo pode ser plantado em até $40 \%$ da área ocupada pela soja. Atualmente, apenas $12 \%$ da áręa total da soja é utilizada em rotação com o trigo.

\subsubsection{Importação de trigo}

Em 1965 o governo paraguaio criou uma comissão para a compra do trigo importado, formada por representantes dos Ministérios da Indūstria e Comércio, da Fazendà, Banco Central e um representante dos moinhos.

As compras eram (e ainda são) feitas principalmente da Argentina, por meio de licitações e em menor proporção, dos Estados Uni dos, regidos pela lei püblica nọ 480. O trigo é importado pela comissão a uma taxa de câmbio preferencial e vendido aos moinhos ao mesmo preço do produto nacional. O volume do trigo importado sofre variações anuais, devido às variações na produção domêstica e tambēm às quantidades do produto e seus derivados que ingressam rio paîs de forma ilegal. 


\subsection{Comercialização}

\subsubsection{Caracterîsticas gerais}

A comercialização do trigo tem características diferentes com relação a outros produtos. O governo fixa o preço e estabelece normas de qualidade para o produto a ser comercializado nos moinhos.

Para a fixação do preço mīnimo são levados em conta os preços do produto do mercado internacional e o custo da produção na-. cional.

0 maior volume de trigo é produzido por médios e grandes produtores, como foi dito e são eles mesmos os encarregados de comercializar diretamente com os moinhos. O diagrama 1 mostra os diferentes canais de comercialização do trigo no Paraguai.

A maior parte da produção tritícola é transporíada para os moinhos por rodovia, em cámirihões de grãos, exceto o transporte de Volendam a Assunção que é realizado por via fluvial.

2.5. Mercado Doméstico, Evolução do Consumo e Caracterî́stica da Indūstria

0 mercado doméstico do trigo é dado pe lo consumo dos seus derivados, principalmente a farinha, cuja demanda apresenta uma expansão moderada e constitui-se em um importante componente da dieta alimentar da população. 
0 processamento do trigo é realizado por sete moinhos, com uma capacidade instalada de elaboração de 510 toneladas de farinha por dia, localizados na sua maioria em Assunção. Estima-se que a capacidade instalada no paîs é superior em aproximadamente $40 \%$ à capacidade utilizada dos moinhos.

Tabela 15. Produção, Importação e Consumo de Farinhà, Paraguai, 1975/82

\begin{tabular}{lcccc}
\hline Ano & $\begin{array}{c}\text { Produzida pelos } \\
\text { moinhos } \\
(\mathrm{t})\end{array}$ & $\begin{array}{c}\text { Importadas } \\
(\mathrm{t})\end{array}$ & $\begin{array}{c}\text { Consumo } \\
\text { total } \\
(\mathrm{t})\end{array}$ & $\begin{array}{c}\text { Consumo } \\
\text { per capita } \\
(\mathrm{kg})\end{array}$ \\
\hline 1975 & 37.658 & 9.062 & 46.720 & 18,4 \\
1976 & 49.777 & 25.432 & 75.209 & 28,8 \\
1977 & 59.114 & 640 & 59.754 & 22,4 \\
1978 & 84.584 & 66 & 84.650 & 30,9 \\
1979 & 82.333 & 323 & 82.656 & 29,4 \\
1980 & 81.837 & 387 & 82.224 & 28,6 \\
1981 & 100.671 & 344 & 101.015 & 34,2 \\
1982 & 96.779 & 81 & 96.860 & 32,0 \\
\hline
\end{tabular}

FONTE: Banco Central del Paraguay, 1983 

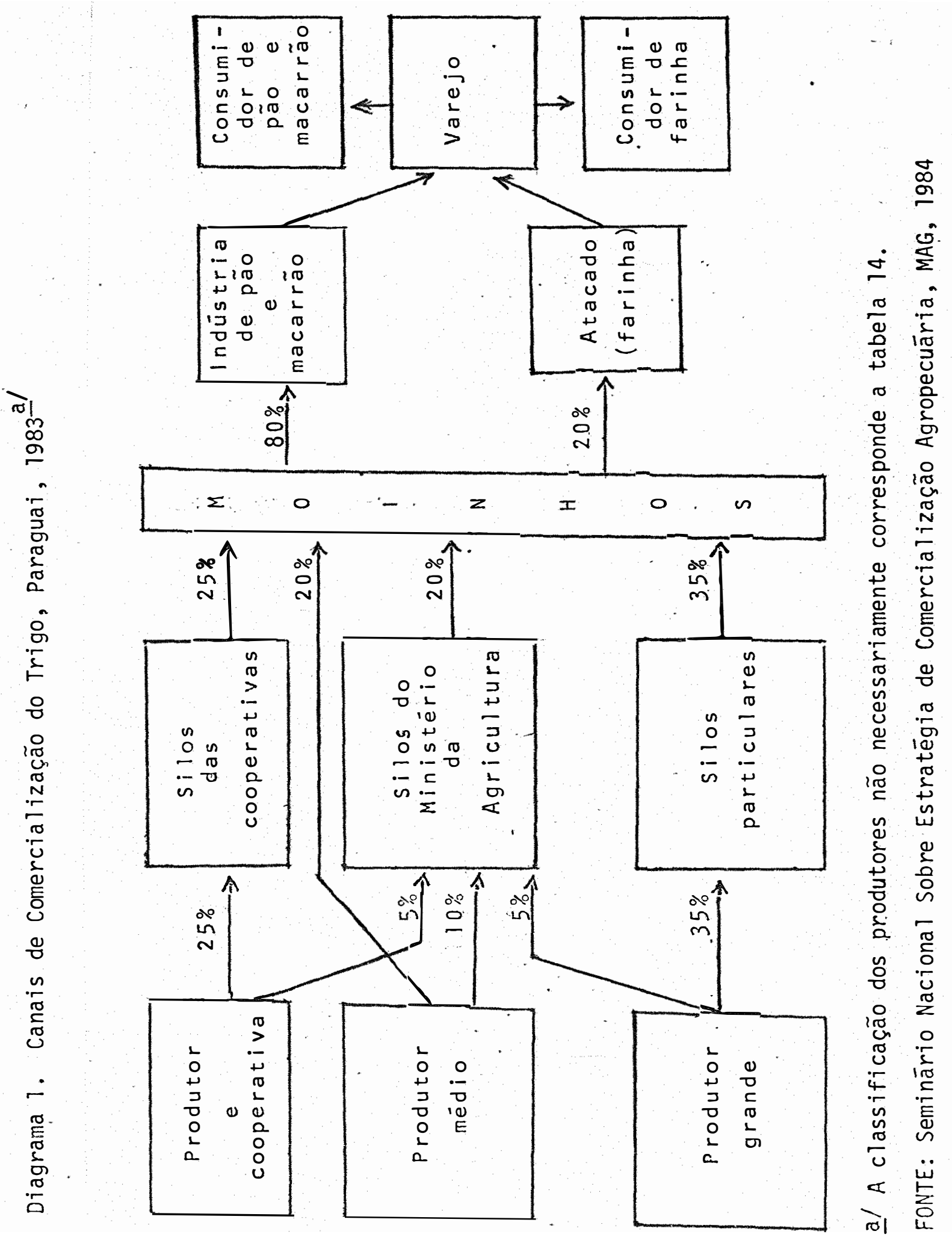


\section{REVISAO DE LITERATURA}

Muitas vezes têm que ser tomadas decisões quanto a um da do investimento sem que se tenha um teste adequado sobre o impacto que este vai ter na economia. Isto levou ao desenvolvimento de uma extensa literatura na ārea de anālise de custo-benefício e de critérios de investimentos em uma estrutura de equilíbrio geral. Assim, diverscs trabalhos foram desenvolvidos tentando estimar os beneficios e custos sociais para avaliar uma determinada atividade.

Como geralmente os investimentos em pesquisas e educação têm sido vistos como pré-requisitos para sustentar o crescimento econōmico, foram desenvolvidos vários trabalhos empíricos nesta área de modo a saber quais os investimentos que contribuem para o desenvolvimento e qual a magnitude dos seus retornos. Assim, os primeiros estudos foram realizados por SCHULTZ e GRILICHES.

SCHULTZ (1953) estimou o retorno social da pesquisa decorrente da utilização de técnicas de produção mais eficientes, através 
do valor dos insumos poupados. Os resultados da anālise mostraram que o retorno da produção por unidade de insumo utilizado em 1950 superava em $32 \%$ o de 1910.

GRILICHES (1958) avaliou o retorno social ao investimento da pesquisa com milho híbrido nos Estados Unidos. Para as estimativas foram levados em conta o excedente económico (excedente do consumidor e excedente do produtor) decorrente do deslocamento da curva de oferta devido à utilização de novas variedades. Achou uma taxa de retorno de $700 \%$ e um retorno de $10^{\circ}$ centavos para cada dōlar investido em pesquisa até 1955 e a partir desta data o retorno estimado foi de sete dōlares.

SCHMITZ e SECKLER (1970), utilizando a mesma metodologia que GRILICHES, analisaram o aumento da eficiēncia na produção de tomate pelo uso de colhedeira mecânica e seus éfeitos na distribuição dá renda. A diferença deste, comparado com os critērios usuais na anālise de custo benefício aplicados nos trabalhos anteriores é que este incorporou para a avaliação dos benefícios líquidos, o custo social do programa devido ao desemprego gerado pelo uso da colhedeira mecānica. Assim, foi considerada a eficiēncia não șó em termos alocativos mas tambêm em termos distributivos.

AYER e SCHUH (1972) analisaram as taxas de retorno social para o investimento em pesquisa de algodão no Estado de São Paulo e o impacto do programa na economia como um todo. A metodologia empregada é aquela baseada no deslocamento da curva de oferta devido a intro dução de nova tecnologia. A taxa de retorno estimada variou entre $77 \%$ 
e $110 \%$ ao ano.

BOING (1974) critica o trabalho de AYER e SCHUH afirmando que a alta taxa de retorno encontrada é resultante do descuido no tratamento de alguns aspectos essenciais da teoria moderna e diz também que os custos sociais do programa foram subestimados ao utilizar. valores nominais e não valores representativos do custo de oportunidade dos recursos empregados na pesquisa. Para chegar a uma estimativa correta, BOING sugere que os recursos sejam avaliados tendo em conta seu melhor uso alternativo.

AKINO e HAYAMI (1975) utilizando o mesmo esquema de analise que os anteriores, estimaram a taxa de retorno social ao investimento público em pesquisa com arroz no Japão. 0 estudo foi feito considerando as situações de economia aberta e economia fechada para os dois períodos. A taxa encontrada variou entre $25 \%$ e $27 \%$ para o primeiro período e entre $73 \%$ e $75 \%$ para o segundo período.

Embora se reconheça a importāncia desses estudos que ana lisam os investimentos públicos e a educação, não se pode esquecer do papel de outros setores da economia, no desenvolvimento econōmico, como por exemplo, do setor externo. Assim, diversos autores (CHENERY e STROUT, 1966 e MCKINNOM, 1964) tem argumentado que o'comércio externo constitui um dos mais importantes condicionantes do crescimento das eco nomias subdesenvolvidas, Para o caso brasileiro, tanto KERSTENETZLY e BAER (1966) como FISHLOW (1968) chegaram a conclusão de que a taxa potencial de crescimento do PIB (Produto Interno Bruto) nao e ditada 
nem pela propensão a poupar nem pelo crescimento da produtividạde do trabalho, mas pela capacidade que o paîs tem de pagar as importações ne cessārias ao seu crescimento econōmico.

Na estimativa da alocação eficiente de recursos surgiram trabalhos relacionando a produção de um determinado setor com a dotação de recursos que o paîs possui. Assim, foram desenvolvidos trabalhos baseados no princĩpio de vantagem comparativa. Esta versão diz que 0 paîs terá maior benefício do comércio pela produção de bens que utilizem em maior proporção seus recursos relativamente abundantes.

Uma das metodologias empregadas na anālise da vantagem comparativa é o custo do recurso doméstico desenvolvido principalmente por BRUNO (1965) e.KRUEGER (1966), o qual tem sido aplicado pelos planejadores de Israel, desde o início da década de 1950 com muito sucesso, na avaliação de projetos, 0 conceito do Custo de Recurso DoméstiCo (CRD), refere-se a uma estimativa do custo "real" de oportunidade em função do total de recursos domésticos utilizados para a produção (poupança) de uma unidade marginal lïquida de divisa. 0 resultado obtido pode ser comparado com a taxa de câmbio de equilíbrio da economia e ser vir como um critério de investimento, assim como a taxa interna de retorno é comparada com a tax̣a de juro real. Este esquema metodolōgico, poderia ser usado para avaliar uma determinada política de substituição de importação ou promoção de exportações.

0 trabalho mais conhecido no Brasil, utilizando a metodologia do CRD é de SAVASINI e KUME (1978) onde analisaram a política 
de promoção ãs exportações, estimando o custo dos recursos domésticos por unidade de divisa gerada.

Para a estimativa do CRD, SAVASINI e KUME utilizaram dados da matriz de relações interindustriais da Fundação IBGE, que abrange 58 setores interindustriais e fornece a quantidade de insumo necessārio aos demais setores, para a produção de uma unidade de demanda final de cada setor. Uma vez obtidos os resultados, os autores dividiram as estimativas da taxa implícita $\left(E_{j}\right)$ do CRD de cada setor, pela taxa de câmbio vigente $(E)$.

A taxa de câmbio de equilíbrio $\left(E_{C}\right)$ estaria aproximadamente $30 \%$ acima do câmbio vigente na época, mas como esta estimativa é preliminar eles adotaram um intervalo entre $25 \%$ e $35 \%$ acima da taxa de câmbio. Assim, setores com $E_{j} / E$ menor que 1,25 teriam um benefício lĩquido positivo enquanto aqueles com $E_{j} / E$ acima de 1,35 teriam benefício negativo. Para aqueles setores com $E_{j} / E$ entre 1,25 e 1,35 não foi possĩvel obter uma conclusão definitiva.

SAVASINI e KUME sugerem então, que os setores com custo de divisa gerada menor que a taxa de câmbio de equilíbrio poderiam ser subsidiados, já que o dōlar gerado produz um benefício líquido positivo, enquanto os setores com custo por divisa gerada maior que a taxa de câmbio de equilî́brio não deveriam ser subsidiados, jā que apresentam uma nítida perda social.

KNIGHT (1972), utilizando um esquema de anālise semelhan te ao anterior, tentou medir a eficiência do uso dos recursos domésticos 
no trigo e comparou com quatro produtos de exportação (arroz, soja, car ne e milho). o resultado mostrou que o indice da eficiência estática do uso dos recursos domésticos foi mais baixo para o trigo do que para qualquer um dos outros quatro produtos. Assim, conclui que o Brasil, em 1967, pagou o valor de US\$2,20 em recursos domésticos para economizar o valor de um dōlar nas importações de trigo, ao passo que o custo comparāvel para a obtenção de um dōlar foi 85 centavos para a carne bovina, 84,6 centavos para o arroz, 82,3 centavos para a soja e 86,7 para o milho.

MENDONÇA (1974) critica o trabalho de PETER KNIGHT, e diz que infelizmente a escassez de informação levou o autor a utilizar um procedimento, para os produtos de exportação que visa sempre a obter um valor favorāvel à produção nacional. Afirma que o erro bāsico que cometeu KNIGHT é não distinguir preços locais e internacionais, jā que na medida em que os dois valores são iguais, a fórmula utilizada não possibilita a estimativa do custo em recursos domésticos para gerar divisas. Outra observação que ele acrescenta é a utilização da taxa de câmbio oficial no çălculo. Entretanto, o autor considerà o procedimento no caso do trigo correto, pois relaciona o custo doméstico de produção corrigido para insumos importados com a economia líquida de divisas. Por outro lado, MENDONÇA considerando as negligências observadas no trabalho de KNIGHT, procura estimar o CRD na produção do trigo e comparar com os valores obtidos para o milho, soja, amendoim e algodão. Concluiu que todos os produtos de exportação analisados, exce to a soja produzida com tecnologia mecânica, geraram taxas implícitas 
inferiores às de mercado, considerando que a taxa de câmbio (dōlar/cruzeiro) estava sobrevalorizada em $20 \%$.

MENDONÇA afirma que todos os produtos de exportação analisados apresentam vantagem comparativa. Para o caso do trigo, a estimativa da taxa implícita supera duas vezes a taxa de câmbio oficial. Assim, o processo de produção de trigo em comparação com a atividade exportadora é inegavelmente mais custosa, numa proporção que vai de 2 a 4 vezes, dependendo da cultura.

Apesar da releväncia de trabalhos desse tipo, principalmente para paĩses em desenvolvimento, não existem estudos empīricos des sa natureza, no Paraguai. A importāncia dos mesmos aumenta quando se leva em conta a situação do balanço de pagamentos do paĩs.

Este estudo tem como objetivo medir os custos sociais da polícita de substituição do trigo. Para atingir tal objetivo, será usa do o critério do CRD, jă que dito critério permite apontar produtos que atuem sobre o balanço de pagamentos. Por outro lado, o modelo apresenta certas vantagens quanto ao requerimento de dados, pois a implementação torná-se relàtivamente fácil uma vez que é possível aproximar-se valores para os custos de oportunidades do cápital, mão-de-obra e divisas. 
4. METODOLOGIA

4.1. Conceitos Básicos

4.1:1. 0 modelo

Quando existem restrições ao comércio e a taxa de câmbio é arbitrada pelo governo, são geradas distorções, que podem ser avaliadas através de estudos que têm como objetivo analisar o custo de oportunidade da produção (ou pọpança) de divisa.

Foram desenvolvidos vārios trabalhos parà outros paîses baseados no Custo de Recursos Domésticos (CRD) o qual constitui uma for ma de medir o custo de oportunidade aplicado ao fator divisa, em termos do total de recursos domésticos necessāriós para gerar uma unidade líquida marginal de divisa. O CRD pode ser utilizado como medida ex-ante de vantagem comparativa de modo a determinar prioridades de investimentos nos projetos futuros. Também pode ser utilizado como medida ex-post do custo de oportunidade incorrido pela economia para seus substitutos de importação ou das exportações. Em tais casos, o conceito ex-post do 
do CRD torna-se um indice do custo social de proteção para substitutos de importações ou da promoção às exportações (BRUNO, 1972). .

Assim, o resultado obtido através do CRD reflete o custo doméstico de gerar divisas na produção de uma mercadoria, tendo uma determinada estrutura de ativiade.

Um resultado favorāvel no critério do CRD implica em um benefício líquido social positivo, e uma vez estimado esse benefício pa ra cada produto, è possível ordenar as atividades de acordo com as que possuem maior benefício (menores custos domésticos) de tal forma a indicar a estrutura de vantagem comparativa que possui. o paîs.

o ünico problema que poderia surgir e afetar o resultado pela metodologia proposta, seria o de um setor ou atividade que precise de insumos de outro setor que esteja sendo protegido e apresente certo grau de ineficiência.

Em tais circunstāncias, poder-se-ia obter uma estimativa desfavorável pelo critério do CRD, que subestime a verdadeira eficiēncia da atividade ou produto analisado. Mas no Paraguai todos os insumos não primários necessários para a produção dos prodụtos analisados, são importados. Portanto, isto facilitäria o ordenamento de atividades que apresentam realmente um maior benefício social. 


\subsubsection{Preço de Conta}

Uma determinada atividade poderia ser avaliada de diversas formas. Uma empresa privada, por exemplo, realiza um investimento, principalmente tendo em conta a sua rentabilidade financeira. Portanto, utiliza os preços de mercado para avaliar os insumos comprados e os produtos vendidos em um determinado tempo.

Uma instituição püblica avalia a rentábilidade de um investimento com relação à economia nacional. Neste caso, são empregados os chamados preços de conta.

0 preço de conta (POWERS, 1981) è um preço calculado ten do presente certos objetivos, tais como a maximização do crescimento econômico, o melhoramento da posição do balanço de pagamentos e a promoção de oportunidades de emprego no paīs. Alēm disso, também leva em consideração as políticas de desenvolvimento e dotação de recursos do paìs. Dessa forma, o preço de conta é uma medida do valor real da contribuição do bem ou serviço a esses objetivos.

A gama de preços de conta adota diferentes valores segundo quais sejam os pressupostos que se faz sobre a economia, dando assim origem a dois conjuntos de valores: os preços de eficiência e os preços sociais. A diferença entre os dois é que no primeiro só se leva em conta o custo de oportunidade do bem ou serviço analisado. enquanto no segundo, além disso, considera-se também a distribuição da renda. 
4.2. Formulação Algébrica do Modelo.

Mostra-se a seguir como pode ser obtido o CRD para uma atividade, produzindo o produto $j$ e utilizando o insumo $i$.

Sejam:

$B_{j}$ = benefício líquido da atividade $j$ por unidade em moeda domēstica

$a_{i j}=$ quantidade de insumo não-primārio i necessārio para produzir uma unidade do produto $j ; i=1, \ldots, n$

$P_{i}=$ preço de conta do $n$ insumo i não-primārio, em moeda doméstica;

$f_{s j}=$ quantidade do insumo primārio necessário para produzir uma unidade do produto $j ; s=1, \ldots, m$

$V_{S}=$ preço de conta do insumo primärio, em moeda doméstica

$P_{j}{ }^{*}=$ preço de conta de $j$, em moeda doméstica.

Então:

$B_{j}=P_{j}-\left[\sum_{i=1}^{n} a_{i j} P_{i}+\sum_{s=1}^{m} f_{s j} v_{s}\right]$

De acordo com a expressäo (1) a atividade $j$ seria conveniente se $B_{j}>0$. Assim, poderíamos ordenar uma série de atividades por ordem decrescente de $B_{j}$. 
Mas a expressão (1) corresponde à generalização do problema. E necessārio particularizā-la de modo a se poder analisar especificamente os problemas envolvidos na geração de divisas, via substituição de importação ou via promoção de exportações (BRUNO, 1965).

Considerando a expressão (1) e tendo em conta o fator di visa, o coeficiente líquido de divisa $f_{\mathbf{s j}}$ serā a diferença entre o preço em dōlar do produto $j$ (chamado agora $U_{j}$ ) e a quantidade total necessāria de insumos importado em dōlar (chamado $\bar{m}_{j}$ ) para a produção de uma unidade do produto $j$. Agora a expressão para o benefício liquido passa a ser:

$$
B_{j}=\left(U_{j}-\bar{m}_{j}\right) d_{0}-\left[\sum_{i=1}^{n} a_{i j} P_{i}+\sum_{s=2}^{m} f_{s j} v_{s}\right]
$$

onde:

$$
\begin{aligned}
d_{0}=\left(V_{1}\right)= & \text { taxa de câmbio social (ou de equilíbrio de mercado) me- } \\
& \text { dida em moeda doméstica por dōlar. }
\end{aligned}
$$

Consideremos agora a seguinte expressão:

$$
d_{j}=\frac{\sum_{i=1}^{n} a_{i j} p_{i}+\sum_{s=2}^{m} f_{s j} v_{s}}{u_{j}-\bar{m}_{j}}
$$

0 primeiro termo do numerador é o valor social dos insumos não-primários domésticos necessārios para a produção de $j$. 
0 segundo termo do numerador ē o valor direto de fatores primārios internos (tais como mão-de-obra e capital) avaliados pelos seus custos de oportunidade.

0 denominador representa a quantidade de divisas líquidas ganhas ou poupadas. Assim, o quociente $d_{j}$ mede o custo, em recursos domésticos, de um dólar de divisa líquida (taxa de câmbio implícita).

Por outro lado, para estimar $B_{j}$ usando a expressão (2) $\bar{e}$ necessário conhecer o valor atrịuî́do aos preços de conta dos $n$ insumos. não-primārios. Uma maneira de solucionar dito problema seria expres$\operatorname{sar} B_{j}$ de modo que o requerimento de insumos não-primārios para a produção de $j\left(\sum_{i=1}^{n} a_{i j} P_{i}\right)$ seja representado pela necessidade de insumos primários a eles equivalentes.

0 beneficio líquido seria agora expresso por:

$$
B_{j}=\left(U_{j}-\bar{m}_{j}\right) d_{0}-\sum_{s=2}^{m} \bar{f}_{s j} V_{s}
$$

onde:

$$
\begin{aligned}
& \bar{f}_{s j}>f_{s j}, e \\
& \bar{f}_{s j} \text { corresponde aos coeficientes de utilização total de insumos } \\
& \text { (diretos e indiretos) primários na produção } j .
\end{aligned}
$$

Dessa maneira, a expressão (3) que define a taxa de câmbio implícita, pode ser modificada:

$$
d_{j}=\frac{\sum_{s=2}^{m} \bar{F}_{s j} v_{s}}{U_{j}-\bar{m}_{j}}
$$


Dividindo ambos os termos da expressão (4) por $\left(U_{j}-\bar{m}_{j}\right)$ temos que:

$$
\frac{B_{j}}{U_{j}-\vec{m}_{j}}=d_{0}-\frac{\sum_{s=2}^{m} \bar{f}_{s j} v_{s}}{U_{j}-\vec{m}_{j}}
$$

Substituindo (5) em (6) temos:

$$
\frac{B_{j}}{u_{j}-\bar{m}_{j}}=d_{0}-d_{j}
$$

ções :

Desde que $\left(U_{j}-\vec{m}_{j}\right)>0$ tem validade às seguintes rela-

$$
\begin{aligned}
& B_{j}>0 \text { se } d_{0}>d_{j} \\
& B_{j}=0 \text { se } d_{0}=d . \\
& B_{j}<0 \text { se } d_{0}<d_{j}
\end{aligned}
$$

0 que significa que a comparação da taxa de câmbio de equilíbrio $\left(d_{0}\right)$ com a taxa de câmbio implícita $\left(d_{j}\right)$ da atividade $j$, vai determinar o benefício líquido da atividade $j$. 
4.3. Descrição dos Dados Utilizados.

4.3.1. Produtos e regiões analisados

Este estudo corresponde ao ano agrícola 1982/83. Foram incluĩdos quatro produtos na pesquisa: trigo, soja, algodão e fumo. 0 primeiro como substituto de importação ẹ os outros foram escolthidos pela importância que representam no setor exportador.

0 estudo abrange as regiões de maior produção para cada uma das culturas analisadas de modo que o resultado obtido tenha validade a nível nacional.

A maioria das culturas analisadas (exceto o algodão) é produzida em duas regiões, representando estas quase $70 \%$ de produção to tal. Assim, a soja e o trigo são produzidos no departamento de Itapua e alto Paranā, o fumo no departamento de San Pedro e. Caaguazu. 0 algodão é a cultura cuja produção se encontra mais espalhada por diversas regiões. Portanto seus dados representam a média nacional.

A tecnologia de produçã̃o difere para as quatro culturas analisadas. 0 trigo basicamente é produzido por médios e grandes produtores que dispõem de maquinaria agrîcola automotriz, utilizando portanto tecnologia mecãnica para todas as atividades que demandem seu uso.

A produção da soja se desenvolve sob trēs tipos de tecnologia: 
a) Manual: è utilizada geralmente por pequenos produtores. Dita tecnologia de produção perdeu importância nos ūltimos anos, dando lugar à introdução de tecnologia mais moderna. Os especialistas em soja têm estimado que $5 \%$ da área total de plantio, vem sendo explorada usando a tecnologia mencionada;

b) Semi-mecanizada: è considerada pará os produtores que utilizam equipamentos de tração animal. Segundo informações de téc nicos ligados ao programa de produção desta cultura, estima-se que $15 \%$ da área total plantada, vem sendo produzida com esta tecnologia;

c) Mecanizada: 'é utilizada pelos produtores que dispõem de maquinaria agrícola automotriz representando $80 \%$ da ārea total do plantio. No presente estudo foi a única tecnologia de produção conside rada por ser a mais representativa.

0 algodão é produzido basicamente pelos pequenos produtores os quais utilizam, na maioria dos casos, a tração animal (tecnologia semi-mecanizada). Assim, a prepáração do solo e o plantio são feitos utilizando este tipo de tecnologia e as outras atividades são de senvolvidas manualmente.

Os dados utilizados $4 /$ no presente trabalho correspondem à média regional. Portanto, estão incluĩdos os produtores que também não desenvolvem algumas atividades tais como controle fitossanitārio,

4/ Informações obtidas do Serviço de Extensão Agrĩcola e Pecuāria do Ministério da Agricultura e Pecuāria, Páraguai, 1984. 
segunda ou terceira limpeza, etc. Mas, verificou-se não existị diferença sensīvel nas diversas atividades de produção e também quanto à época em que são realizadas as operaçōes agricolas nas diferentes regiões produtoras.

Para a produção do fumo, dependendo do tipo, são utilizádas duas tecnologias. Assim o fumo eșcuro é produzido com tecnologia semi-mecanizada (tração animal) representando 34\% da ārea total plantada e o restante é desenvolvido manualmente. O fumo claro "burley", de recente expansão no paîs, è produzido quase totalmente na forma manual: No presente trabalho foi considerado só o fumo claro jā que a demanda internacional cresceu para este tipo de produto.

No apêndice 1 se apresenta o custo de produção das quatro culturas analisadas de acordo com as tecnologias descritas anterior mente e a participação dos insumos no mesmo.

\subsubsection{Preços}

\subsubsection{Preços de produtos}

Para o trigo foi considerado o preço CIF de importação e para a soja e fumo, o preço FOB de exportação.

No caso do algodão o preço $F O B$ foi estimado, jā que a exportação deste produto se faz em forma de fibra. Para a obtenção do seu preço, foi aplicado ao preço FOB de exportação, a mesma percentagem de participação 5 / que tem a matéria-prima (algodão em rama) no custo 5/ Informação obtida da Indūstria de Fibra, Paraguai, 1984. 
de produção da fibra.

\subsubsection{Custo do capital}

A taxa de retorno utilizada para o capital foi de $15 \%$ ao ano. Este valor foi extraido do trabalho de ALFONSO (1985). A metodologia utilizada por ele para a estimativa do custo de oportunidade do capital foi baseada nos dados de grupos de empresas, onde a taxa de retorno ao capital foi obtida como uma remuneração ao patrimōnio líquido (inclui os valores das contas de capital, reservas, provisões, lucros retidos, lucros a distribuir, etc.) das empresas.

Uma parte do capital (máquinas e equipamentos) empregado nas diversas culturas é importada. Assim, foram estimados os custos fi xos (juro e depreciação) è custos variāveis (combustîvel, ōleo, manutenção, etc.) por hora de uso daqueles recursos em dōlar, utilizando o preço CIF de importação das máquinas, equipamentos e dos insumos para os mesmos. Uma vez obtido o custo horário, este foi multiplicado pelo tempo 6/ de uso nas diversas operações do processo produtivo de cada cuI tura. No apēndice. 2 se apresentam as fórmulas? utilizadas para a estimativa do custo horário das māquinas e equipamentos agrícolas.

6/ Obtido do Custo de Produção

I/ Obtido da publicação do Ministērio de Agricultura e Pecuāria "Guia na Seleção de Máquinas e Equipamentos Agrícolas". Paraguai, 1977. 


\subsubsection{Preço da terra}

Para estimar o preço de eficiência (custo de oportunidade) foi imputado ao valor do ativo terra a remuneração utilizada para o capital, ou seja, 15\% ao ano, uma vez que não foi possível obter os valores de arrendamento da terra para as diversas culturas e regiões.

\subsubsection{Preço de mão-de-obra}

Para estimar o preço de eficiência da' mão-de-obra foi tomado como base o trabalho de POWERS (1981) e através da razão do preço de conta (RPC) utilizado como fator de conversão, transformou-se o preço de mercado em preço de eficiência.

Para a estimativa da razão do preço de conta (RPC) POWERS identifica duas variāveis com referência a duas regiões do Paraguai, on de o mercado de trabalho apresenta diferentes características.

Uma das variāveis representa a região $B$ a qual abrange sete departamentos e a outra representa a região C a qual abrange quatro departamentos, A região B é escolhida como fornecedora de mão-deobra (com base no censo) para a região $C$, onde hā melhores possibilidades e/ou condições de trabalho.

Assim, POWERS, analisando as tendēncias migratōrias entre regiões construiu um medelo simples de onde a RPC é obtida a partir 
das tendências migratórias e as estimativas do produto marginal do trabalho em cada região, divididas peło preço de mercado. Ele pressupõe que uma nova atividade desenvolvida na região $C$ utiliza aproximadamente $50 \%$ de mão-de-obra de outro lugar mas da mesma região e os $50 \%$ restantes são provenientes da região expulsora de mão-de-obra (região B). Em consequência, o custo de oportunidade do trabalho depende do produto que deixa de ser obtido como resultado da migração inter e intra regionais.

Conforme o expos'to, temos que a RPC de mão-de-obra igual a Preço de eficiēncia/Preço de mercado onde o Preço de eficiēncia é igual a: $0,5\left(P M_{C} \times F C P\right)+0,5\left(P M_{B} \times F C C R\right)$.

$P M_{C}=$ Produto marginal do trabalho na região $C$

$P M_{B}=$ Produto marginal do trabalho na região $B$

$\mathrm{FCP}=$ Fator de conversão de produtos primārios- 1

FCCR $=$ Fator de conversão de consumo rurar $8 /$

Mul.tiplicando o fator (RPC) pelo preço de mercado da mão-de-obra é obtido o preço de eficiência da mesma. o valor cio fator (RPC) encontrado por POWERS, utilizado neste estudo foi de 0,4289. 0 valor atribuî́do à mão-de-obra corresponde à região não expulsora da mes ma, que constitui a região de maior percentagem de participação na produção a nível nacional das culturas analisadas, exceto do algodäo.

8/ Para maiores detalhes, ver POWERS, op.cit. 


\subsubsection{Custo da divisa}

Para a obtenção do custo social da divisa foi levado em conta o trabalho jā anteriormente mencionado de ALFONSO (1985) o qual, utilizando o mesmo esquema metodolōgico de BACHA et alii (1972), estimou o custo social da divisa Paraguaia para o período 1972/82.

A fōrmula utilizada para o cálculo foi deduzida do mode10 de equilíbrio parcial do mercado cambial, cuja pressuposição bāsica é considerar as curvas de oferta e de procura envolvidas (exportação e importação) como funções apenas dos seus respectivos preços. Os preços internacionais das exportações e das importações são dados para o país.

Baséado no modelo mencionado, o autor utilizou a seguinte expressão para a estimativa do custo social da divisa:

$$
r_{s}=r_{0}(1+t)^{a}
$$

onde:

$$
\begin{aligned}
& r_{S}=\text { custo social da divisa (em guaranies/dōlar) } \\
& r_{0}=\text { taxa de câmbio de exportação (em guaranies/dōiar) } \\
& t=\text { nīvel de proteção tarifāria, medido pela tarifa mēdia em \% } \\
& M=\text { valor das importáções em dōlares } \\
& X=\text { valor das exportaçōes em dōlares } \\
& a=\frac{M}{X+M}
\end{aligned}
$$


Tabela 16. Cālculo do Custo Social da Divisa

\begin{tabular}{cccccc}
\hline Ano & $\begin{array}{c}\text { Taxa de Câm- } \\
\text { bio de expor } \\
\text { tação }\left(r_{0}\right)\end{array}$ & $\begin{array}{c}\text { Tarifa } \\
\text { média } \\
t(\%)\end{array}$ & $\begin{array}{c}\mathrm{a} \\
|\mathrm{M} /(\mathrm{X}+\mathrm{M})|\end{array}$ & $(1+\mathrm{t})^{\mathrm{a}}$ & $\left|\mathrm{r}_{\mathrm{o}}(1+\mathrm{t})^{\mathrm{a}}\right|$ \\
\hline 1972 & 126 & 60 & 0,447 & 1,234 & 155,5 \\
1973 & 126 & 60 & 0,452 & 1,237 & 155,8 \\
1974 & 126 & 60 & 0,502 & 1,266 & 159,5 \\
1975 & 126 & 60 & 0,502 & 1,266 & 159,5 \\
1976 & 126 & 60 & 0,498 & 1,264 & 159,3 \\
1977 & 126 & 60 & 0,551 & 1,296 & 163,3 \\
1978 & 126 & 60 & 0,584 & 1,316 & 165,2 \\
1979 & 126 & 60 & 0,612 & 1,333 & 168,0 \\
1980 & 126 & 60 & 0,633 & 1,347 & 169,7 \\
1981 & 143 & 60 & 0,640 & 1,351 & 193,2 \\
1982 & 160 & 60 & 0,661 & 1,364 & 218,2 \\
\hline
\end{tabular}

FONTE: ALFONSO, C.O., op.cit.

Conforme mostra a Tabèla 16, em 1982 a taxa de equilibrio de mercado superava en $36,4 \%$ a taxa oficial. Mas como o estudo abrange tamibëm o ano de 1983 considerou-se para esse ano o mesmo nîvel de sobrevalorização da taxa cambial do ano anterior. Lembrando que a taxa de câmbio de exportação para 1983 fọi igual a 177 guaranies/US\$ a taxa de equilíbrio de mercado adotada para este ano foi de 241 garanies/US\$. 
4.3.2.6. Preços dos insumos não-primārios

0 ünico insumo não-primārio de origem nacional ē a semen te. Todos os outros restantes são importados. 0 preço de mercado foi tomado como indicativo do preço de eficiência para este insumo jā que não existem impostos aplicáveis ao mesmo. Além disso, a participação do governo no mercado é pouco significativa:

Para os insumos importados tais como fertilizantes e defensivos, os preços utilizados foram os preços CIF de importação- .

\subsubsection{Custo de transporte}

Para a estimativa do custo de transporte foi considerado o percurso que o produto faz até chegar ao centro de distribuição. No caso do trigo esse percurso se refere à distāncia que vai dos centros de produção até os moinhos.

Para os produtos de exportação como a soja e fumo, 0 percurso se refere à distância que vai dos centros de produção até os de pósitos dos exportadores. Para o algodão, dos centros de produção atē a indūstria jā que o produto é exportado em forma de fibra.

0 preço do frete-10/ foi transformado de guaranies/tonela da em US\$/.tonelada pela taxa de câmbio de equilíbrio (24l guaranies/US $\$$ ), uma. vez que os caminhöes de transporte são importados:

9/ Estes preços são publicados pelo Boletim Estatîstico do Banco Central. do Paraguai.

$10 /$ Obtidos do Departamento de Comercialização do Ministério da Agricultura e Pecuária. Paraguai, 1983. 


\subsubsection{Coeficientes de Produção}

Os coeficientes técnicos e as características das māquinas e equipamentos foram obtidos através das publicações dos custos de produção elaborados pelo Departamento Técnico do Ministério da Agricultu ra e Pecuāria, do Paraguai. Nos custos de produção são levados em conta todos os componentes ligados direta ou indiretamente ao processo produtivo. Todos os custos, para facilidade de câlculo, foram expressos em custos por tonelada do produto. A transformação ē feita pela razão custos por hectare/rendimento da cultura analisada. 
5. RESULTADOS E CONCLUSÖES

5.1. Estimativa dos Custos Totais e a Taxa de Câmbio Implícita.

Como foi exposto no capitulo anterior, os preços de efi-ciência dos diversos recursos produtivos, assim como a taxa de câmbio de equilíbrio foram estimados de forma a permitir o cálculo da taxa de câmbio implicita para cada produto analisado. Assim, foram calculados os custos de produção, a preços de mercado e de eficiência, para os recur.. sos domésticos e para os importados, de cada cultura (Apêndice 3) e a partir destes as taxas de câmbio implícitas (Tabela 17). 
Tabela 17. Estimativa da Taxa de Câmbio Implicita para Culturas Selecionadas, Paraguai, 1983

\begin{tabular}{lcccc}
\hline Culturas & $\begin{array}{c}\text { Custos dos } \\
\text { insumos } \\
\text { nacionais } \\
\left(g_{S} / t\right)\end{array}$ & $\begin{array}{c}\text { Custo dos } \\
\text { insumos } \\
\text { importados } \\
(\text { US } \$ / t)\end{array}$ & $\begin{array}{c}\text { Valor } \\
\text { agregadoa }\end{array}$ & $\begin{array}{c}\text { Taxa } \\
\text { implícita } \\
d_{j}=g_{S} / \text { US } \$\end{array}$ \\
\hline Trigo & 26.724 & 152,9 & 58,1 & 459 \\
Soja & 16.309 & 94,7 & 93,5 & 174 \\
Algodão & 48.814 & 67,0 & 409,5 & 119 \\
Fumo & 53.620 & 71,2 & 708,8 & 76 \\
\hline
\end{tabular}

a/ Obtido atravēs da expressão $\left(u_{j}-\bar{m}_{j}\right)$

Os resultados mostraram que, exceto para o trigo, as taxas de câmbio implícitas foram menores do que a taxa do câmbio de "equilíbrio", e do que a taxa de câmbio oficial, o que evidencia a vantagen comparativa do paîs para aquelas culturas.

0 fumo é o produto que apresenta o menor custo por divisa gerada, seguido do algodão e por ūitimo, da sojá.

A taxa de câmbio implî́cita para o trigo superou em 1,90 ve zes a taxa de câmbio de equilíbrio. Portanto, o paîs gasta 1.90 dōlares em recursos domésticos para économizar um dölar na importação desse produto: 
Um dos argumentos para a proteção ao trigo frequentemente utilizado é o de que tal cultura seria uma importante fonte absorvedo ra de mão-de-obra, relativamente a outras culturas. Assim, calculou-se a quantidade total de mão-de-obra empregada em cada cultura.

Os resultados mostraram, entretanto, que o trigo $\overrightarrow{\mathrm{e}} \mathrm{o}$ que utiliza a menor quantidade de mão-de-obrá, das quatro culturas. Na verdade, os resultados mostraram uma relação inversa entre taxa implícita e quantidade utilizada de mão-de-obra. Ou seja, os produtos que apresentaram maior vantagem comparativa (e portanto, menores taxas implícitas) foram os que mais intensamente utilizam mão-de-obra (Tabela 18). Logo, o argumento de que a proteção ao trigo seria desejāvel pela grände intensidade com que utiliza mão-de-obra não parece ser verdadeiroll.

Tabela 18. Quantidade utilizada de mão-de-obra, por hectare, nas culturas de trigo, soja, algodão e fumo, Paraguai, Ano Agrīcola $1982 / 83$

\begin{tabular}{lcc}
\hline Cultura & Dialhomem & Taxa-implicita \\
\hline Trigo & 5 & 459 \\
Soja & 6 & 174 \\
Algodão & 50 & 179 \\
Fumo & 153 & 76 \\
\hline
\end{tabular}

$11 /$ Pelo menos para as culturas selecionadas neste estudo 
De um modo geral, pode-se dizer que os resultados deste trabalho mostraram que o Paraguai possui vantagem comparativa na produção de fumo, algodão e soja, três importantes produtos de exportação daquele paîs. Entretanto, a taxa de câmbio implícita para o trigo mostrouse 1,90 vezes superior à taxa de câmbio de equilíbrio o que reflete o cus to social da proteção do governo àquele produto. Acredita-se que uin dos principais motivos que impedem o éxito do programa é a baixa produtividade desta cultura. 0 éxito do México, paîs latino-americano que passou de tradicional importador de trigo a exportador, foi devido principalmente ao desenvolvimento tecnotógico (tecnologia biológica). Mas, este su-cesso não foi o trabalho de um indivĩduo, mas sim de uma grande equipe de pesquisadores e extensionistas que contavam com os melhores peritos de nível internacional e apoio financeiro.

\subsection{Resumo e Conclusões}

0 Paraguai se caracteriza, coino paîs primārio exportador, sendo o setor agropecuário o de maior importância na econorita do paîs, jā que $90 \%$ das exportações, a terça pärte do produto interno bruto e a metade da população economicamente ativa empregada corresponde a dito setor.

Na economia do paîs é adotada a traciição ce politicica econômica "Laissez-Faire" a qual se revela pela virtual ausência de controle de preços à rápida absorção dentro da economia doméstica de mudanças nos preços externos e um setor püblico de pouco inpacto nas atividades 
econômicas em comparação com a maioria das nações latino-americanas.

0 ūnico produto agrícola importado em grandes quantidades é o trigo. O governo, desde 1957, vem implementando o Programa de Produção do Trigo Nacional com a finalidade de substituir o trigo importado. Vārios argumentos têm sido usados (sendo a independēncia da Argentina o mais forte) para a criação do programa. -

Mas, a tendência expansiva da economia, experimentada na década de setenta, quebrou-se desde 1982, quando se deu o aparecimento de um déficit no balanço de pagamentọs. Isto fêz com que a politica de - substituição de importação do trigo pelo nacional ganhasse maior força no seu argumento econōmico do que no seu início.

Quaisquer que sejam os argumentos da politica de substitui ção do trigo importado pelo nacional a mesma possui um custo que nunca foi estimado de modo a permitir sua avaliação. Assim, o objetivo deste trabalho consistiu em calcular o custo em recursos domésticos para gerar um dōlar poupado através do trigo via substituição de importação e compará-10 com o custo de oportunidade da divisa dos principais produtos de exportação. Uma vez ordenados os custos da divisa para os diferentes pro dutos, foi estimado o requerimento de mão-de-obra para os mesmos, na tentativa de se saber se os produtos que apresentam um menor custo por divisa gerada, são os que mais absorvem mão-de-obra, o fator supostamente mais abundante no paîs.

Para se atingir o objetivo mencionado, foi utilizado o modelo proposto por MICHAEL BRUNO (1965) do Cus to de Recurso Doméstico (CRD), 
o qual constitui uma forma de medir o custo de oportunidade aplicado ao fator divisa, em termos do total de recursos. domésticos necessários para gerar uma unidade líquida marginal de divisa. Para a implementação do modelo, foi necessário obter o preço de eficiência ou preço social dos re cursos primārios (terra, mão-de-obra, capital e divisa) os quais foram obtidos de outros estudos. Assim, o preço social do capital e da divisa foram extraídos do trabalho de ALFONSO (1985) e o preço da mão-de-obra do trabalho de POWERS (1981).

Os resultados obtidos mostraram que todas as culturas de exportação (soja, algodão e fumo) geraram taxas impīicịtas inferiores à ta xa de câmbio de equilíbrio. Para o trigo aconteceu o contrário, pois a taxa de câmbio implícita supera em 1,90 vezes a taxa de câmbio de equilíbrio o que permite concluir que o Paraguai estaria dispendendo 1,90 dōlares em recursos domêsticos para economizar um dōlar na importação. Tal resultado reflete o custo social da proteção do governo à implementação dâ política de substituição do trigo importado pelo nacional, onde 0 principal argumento prō-substituição de importações ( $j a ̄$ mencionado no iní cio deste trabalho), foi político, ou seja, de independéncia em relação ao pais exportador.

Por outro lado, o resultado obtido no presente estudo per mite também concluir que os produtos que apresentam menores taxas implicitas (menores custos por divisa gerada) são os que utilizam mais intensivamente a mão-de-obra, o fator considerado mais abundante no paîs. Assim, a proteção ao trigo devido à absorção de mão-de-obra que esta 
cultura apresenta na época onde as tarefas agrícolas diminuem de intensidade pela falta de outras culturas não parece ser vālida, jā.que è um produto que utiliza pouca quantidade deste recurso no seu processo produtivo.

0 resultado obtido neste estudo foi bastante semelhante ao encontrado por MENDONÇA DE BARROS que estimou que a taxa implicita na pro dução do trigo, para o Brasil, superava em duas vezes a taxa de câmbio oficial. Este resultado foi mais favorável que o resultado obtido por PETER KNIGHT, que estimou a taxa para o trigo como sendo duas vezes e meia maior do que a taxa de câmbio oficial.

Acredita-se que a queda na taxa de câmbio implícita para o trigo só possa ocorrer, no futuro, com um aumento na sua produtividade (produção/hectare). Entretanto, nesses 15 anos de existência do programa de proteção ao trigo no Paraguai, o aumento na produção foi devido principalmente à expansão da ārea cultivada, permanecendo quase constante a produtividade.

Parece vālido supor que a transferência e adaptação cia tec nologia do trigo entre paîses é mais complexa do que a de outras culturas como por exemplo, soja e algodão. Isto talvez se deva ao fato de o trigo ser uma cultura bastante sensîvel às condições climäticas e pouco resistente a doenças: Isto sugere que uma política de preço, aliada a uma polîtica de maior volume de crédito alocado ao trigo, não serā suficiente para aumentar a produtividade do mesmo. Maiores investimentos em pesquisa devam talvez acompanhar aquelas medidas para que se possa tornar a politica de substituição de importação do trigo mais bem sucedida. 


\subsection{Limitações do Es tudo}

A principal limitação deste estudo encontra-se no alcance que o mesmo tem no tempo, pois a anālise é feita.para um ano específico somente. Para que o resultado obtido seja vālido para anos posteriores dever-se-ia apresentar as mesmas condições do ano em que o estudo foi fei to:

A outra limitação corresponde aos dados utilizados no mesmo. Assim, os custos de oportunidade da terra e da mão de obra utilizados para o caso do trigo poderiam estar superestimados, já que esta cultura é produzida quando não existe outra atividade significativa no meio rural. Portanto os custos de oportunidade dos recursos mencionados podem na realidade ser menores para o caso do trigo, comparado com as outras cul turas. Is to resultaria, naturalmente, numa queda do cus to de recursos domésticos, e portanto da taxa implícita calculada para aquele produto.

Entretanto, não se acredita que os resultados fossem diferentes, uma vez que, para o paîs possuir vantagem comparativa na produçäo do trigo, o preço de eficiēncia da terra precisaria ser $97 \%$ menor do que o utilizado, ceteris paribus. 


\section{BIBLIOGRAFIA}

ALFONSO, C.0. 1985. Avaliação Privada e Social de Projetos de Investimentos no Paraguai. Tese de Mestrado (a ser defendida), UFSC, 1985.

AKINO, M e Y. HAYAMI, 1975. Efficiency and Equity in Public Research: Rice Breeding in Japan's Economic Development. Am. Jour. Agr. Econ. $57: 1-10$

AYER, H. e G.E. SCHUH, 1974. Social Rates of Return and Other Aspects of Agricultural Research: The Case of Cotton Research in São Paulo, Brażil: Repply Am. Jour. Agr. Econ, 54:557-569,

BACHA, E.L.; A.ARAUJO; M.da MATA e R.MONDENESI, 1972. Análise Govermamental de Projetos de Investimento no Brasil, Procedimentos e Recomendações, $2 \stackrel{a}{-}$ ed. Rio de Janeiro IPEA/INPES. 203p. 
BARROS, J.R. MENDONÇA DE, 1974. Exportą̧ões Agricolas Não-Tradicionais e o Custo Doméstico das Divisas. Série IPE/USP. Mimeografiạ. São Paulo. 115p.

BOINE, W. 1974. Social Rates of Return and Other Aspects of Agricultural Research: The Case of Cotton Research in São Paulo, Brasil - Comment Am. Jour. Agr. Econ, 56:177.

BRUNO, M. 1963. Interdependence Resource Use and Structural Change in Israez. Jerusalém, Banco de Israel.

BRUNO, M. 1965. The Optimal Selection of Export-Promoting and ImportSubstituting Projects in Planning The Externl Sector: Techniques, Prablems and Policies, New York.

BRUNO, M. 1972. Domestic Resource Costs and Effective Protection: Clarification and Synthesis. Joumal of Politisal Economy 20:16-32.

CHENERY, H. e A.STROUT, 1966. Foreing As istance and Economic Development, American Economic Review, 51:18-51.

CONTADOR, C.R. 1981. Avaliação Social de Projetos. São Paulo Ed.Atlas. 293p.

FISHLOW, A. 1968. Two Gap Analysis and Plano Trienal IPEA. 
GRILICHES, Z. 1958. Research Costs and Social Returns Hibrid Corn and Relates Innovations. Jour. Pol. Econ. 66:419-431.

KNIGHT, P.T. 1972. Substituição de Importações na Agricultura Brasileira: A Produção de Trigo no Rio Grande do Sul. Revista Brasileira de Economia. 26:5-31.

KRUEGER, A.0. 1966. Some Economic Costs of Exchange Control: The Turkish Case. Jour. Poz. Econ: 74:466-88.

McKINON, R. 1974. Foreign Exchange Constraints in Economic Development. Economic Joumar. 74:388-409.

MISHAN, E.J. 1973. Economic for Social Decisions: Elements of Cost Benefit Analysis. New York, Praeger Publishers.

NAÇOES UNIDAS, Paraguai, 1984. Identificación de Projectos de Desarrolzo Agropecuário e Forestal. 150p.

PARAGUAI, 1983. Banco Central, Departamento de Estudios Economicos. BoLetim Estadistico, no 301.

PARAGUAI, 1984. Secretaria Técnica de Pianificaciōn, Division de Programaciōn Agropecuāria y Forestal. Diägnóstico del Sector Agropecuärio. 264p. 
PARAGUAI, 1983. Banco Central. Departamento de Estudios Econômicos. Cuentas Nacionales.

PARAGUAI, 1977. Ministērio de Agricultura y Ganaderia. Guia para La Seleccion de Maquinarias e Implementos Agricolas. $101 p$.

PARAGUAI, 1979. Ministério de Agricultura y Ganaderia. Prograna Nacional de Trigo. 90p.

PARAGUAI, 1983. Secretaria Técnica de Planificaciōn Division de Programaciōn Agropecuāria y Forestal. Recopilación de Trabajos Presentados para la Elaboración del Progroma Nacional de Trigo. 146p.

PARAGUAI, 1984. Ministērio de Agricultura y Ganaderia. Gabinete Técnico. Seminärio Nacional sobre Estratégia de Comercialización. Agropecuária. 200p.

PETERSON, W.L. 1979. Internacional Farm Prices and The Social costs of Cheap Food Policies. Am. Jour. Agr. Econ. 61:12-21.

POWERS, T.A. 1981. El Calcuizo de los Precios de Cuenta en la Evaluación de Proyectos. Estudios de Casos Con Base en el Metodo LittleMirrlees/Squire-van der tak. Washington D.C. BID. 
SAVASINI, J.A. e H.KUME, 1978. Anälise da Politica de Promoção de Exportações Segundo o Custo dos Recursos Domésticos Por Unidade de Divisa Gerada. Rio de Janeiro, Fundaçãó Centro de Estudos Comércio Ex terior.

SCHULTZ, T.W. 1953. The Economic Organization of Agriculture. New York, McGraw-Hill.

SCHMITZ, A, e D,SECKLER, 1970. Mechanized Agriculture and Social Welfare:

The Case of The Tomato Harvester. Am. jour. Agr. Econ. 52(4):569-577.

WORLD BANK, Paraguai, 1984. Agricultural Sector Study. 
APENDICES 
APENDICE 1. Estimativa do Custo de Produção de Trigo, Soja, Al.godão e Fumo-1/

0 custo de produção apresentado no presente apēndice, foi utilizado para a extração dos coeficientes técnicos dos diferentes insumos necessārios para a produção das culturas analisadas.

Os valores contidos nas tabelas correspondem a valores de mercado

$1 /$ Elaborado pelo Departamento Técnico do Ministërio da Agricultura e Pecuāria, Paraguai, 1983. 
Custo de Produção de um hectare de Trigo, Departamento de Itapua e Alto Paranā, Paraguai, Ano Agrícola 1982/83

\begin{tabular}{|c|c|c|c|}
\hline Recurso & Quantidade & Unidade & $\begin{array}{c}\text { Valor } \\
\text { (guaranies) }\end{array}$ \\
\hline
\end{tabular}

1. Preparo do Solo

$$
\text { 1.1. } \operatorname{aração~(1~op)~}
$$

- trator 65 HP

- arado de 4 discos

2,5

h

5.575

h

863

1.2. gradeação (2op)

- trator de 65 HP

- grade de 24 discos

2,0

h

4.460

2,0

h

270

2. Plantio e Adubação

- trator de 65 HP

- semeadeira

- mão-de-obra

- semente

- fertilizante

1,0
1,0
2,0
100,0
100,0

h

2.230

hHa /

230

$\mathrm{kg}$

2.000

11.000

14.000

3. Tratos Culturais

3.1. pulverização (3op)

- trator de 65 HP

- pulverizador

- mão-de-obra

- inseticidas

- fungicidas

1,0

h

h

DHI

2.230

2,0

2,0

$\ell$

2.000

2,5

$\ell$

4.450

16.300

4. Colheita

$\begin{array}{ll}\text { 4.1. colhedeira automotriż } & 1,0 \\ \text { - mão-de-obra } & 1,0\end{array}$

4.2. transporte

hHal

7.600

1.000

guaranies $/ \mathrm{kg}$

3.600

5. Juro ( $12 \%$ anual, sobre $90 \%$ do custo total, durante 6 meses)

TOTAL

82.995

a/ dia-homem 
Custo de Produção de um hectare de Soja, Departamento de Itapua e Alto Paranā, Paraguai, Ano Agrícola 1982/8j

Recurso Quantidade Unidade $\begin{gathered}\text { Valor } \\ \text { (guaranies) }\end{gathered}$

1. Preparo do Solo

$\begin{array}{llll}\text { 1.1. aração (1 op) } & & \mathrm{h} & \\ \text { - trator 65 HP } & 3,0 & \mathrm{~h} & 6.690 \\ \text { - arado 4 discos } & 3,0 & & 1.035 \\ \text { 1.2. gradeação (2 op) } & & & \\ \text { - trator 65 HP } & 2,0 & \mathrm{~h} & 4.460 \\ \text { - grade de 24 discos } & 2,0 & \mathrm{~h} & 270\end{array}$

2. Plantio e Adubação

- trator 65 HP

- semeadeira

- mão-de-obra

- semente

- fertilizantes

1,0
1,0
1,0
65,0
60,0

2.230

230

1.000

3.900

3.660

3. Tratos Culturais

3.1. capina

- mão-de-obra

3.2. pulverização

- trator 65 HP

- pulverizador

- mão-de-obra

- defensivos
4,0

$D H^{a}$ /

2.600

1,0

1,0

1,0

3,2 h

Dhal

$\ell$
935

1.000

10.190

4. Colhedeira

4.1. colhedeira automotriz 1,0

h.

7.600

4.2. transporte

$1.600,0$

guaranies $/ \mathrm{kg}$

3.200

5. Juro ( $12 \%$ anual, sobre

$90 \%$ do cus to total,

durante 6 meses)

2.638

TOTAL

53.868

a/ dia-homem 
Custo de Produção de um hectare de Algodão, Departamentos de Caaguazu, San Pedro, Itapua, Paraguari, Caazapa e Alto Paranā, Paraguai, Ano Agrí cola 1982/83

Recurso Quantidade Unidade $\begin{gathered}\text { Valor } \\ \text { (guaranies) }\end{gathered}$

1. Preparo do Solo

1.1. queima

- mão-de-obra

1.2: $\operatorname{aração~(1~op)~}$

- animais de trabalho

- arado

- mão-de-obra

1.3. gradeação (1 op)

- animais de trabalho

- grade

- mão-de-obra
5,0

3,0

3,0

3,0

2,0

2,0

2,0

$\mathrm{DH}^{\mathrm{a}} \mathrm{/}$.

3.250

$\mathrm{Da}$ /

Dia

DHa /

1.350

720

1.950

Da

900

Dia

DHal.

620

1.300

2. Plantio

- semeadeira manual

- mão-de-obra

$3,0^{\circ}$

3,0

1,5

Dia

DHa/

240

- semente

saco

1.950

1.950

3. Tratos Culturais

3.1. desbaste

- mão-de-obra

2,0

$\mathrm{DH}^{\mathrm{a}} \mathrm{l}$

1.300

3.2. capina (3 op)

- mão-de-obra

20,0

DHal

13.000

3.3. pulverização

- pulverizador

- mão-de-obra

8,0
8,0
3,0

Dia

DHa /

$\ell$.

520

5.200

- defensivos

4. Colheita

4.1. secagem e ensacamento

- mão-de-obra

834,0

guaranies $/ \mathrm{kg}$

13.344

5,0

$\mathrm{DH}^{\mathrm{a}} \mathrm{l}$.

3.250

4.2. carregamento

- mão-de-obra

$2,0 \cdots \mathrm{DH}^{\mathrm{a} /}$

1.300

5. Juro ( $12 \%$ anual, sobre 90\% do custo total, du rante 6 meses) 
Cușto de Produção de um hectare de Fumo, Departamentos de Caaguazu e San Pedro, Paraguai, Ano Agrícola 1982/83

Recurso Quantidade Unidade $\quad \begin{gathered}\text { Valor } \\ \text { (guaranies) }\end{gathered}$

1. Sementeira: Preparação

1.1. desinfecção e plantio

- mão-de-obra

- semente

18

$\mathrm{DH}^{\mathrm{a}} \mathrm{I}$

11.700

- material p/sementeira

$-$

-

6.200

2. Preparo do Solo

2.1. capina, queima e marcação

- mão--de-obra

12

$D H^{\text {a }}$ I

7.800

3. Transplante

- mão-de-obra

14

$\mathrm{DH}^{\mathrm{a} /}$

9.100

4. Tratos Culturais

4.1. capina e amontoa

- mão-de-obra

4.2. desbrota

- mão-de-obra

4.3. pulverização

- mão-de-obra

- inseticida

- fungicida

$\begin{array}{lll}23 & \mathrm{DH}^{\mathrm{a} /} & 14.950 \\ 7 & \mathrm{DH}^{\mathrm{a} /} & 4.550 \\ 8 & \mathrm{DH}^{\mathrm{a} /} & 5.200 \\ 2 & \ell & 11.200 \\ 1 & \ell & 3.200\end{array}$

5. Colheita

5.1. preparação prévia - mão-de-obra

$5 \quad \mathrm{DH}^{\mathrm{a} /}$

3.250

5.2. colheita e carregamento

- mão-de-obra

5.3. classificação

- mão-de-obra

5.4. arranque e queina de restos de culturas

- mão-de-obra

57

DHa/

37.050

5

$D H^{a /}$

3.250

4

$\mathrm{DH}^{2} /$

2.600

6. Juro ( $12 \%$ anual, durante 6 meses)

7.269

TOTAL

128.479

a/ dia-homem 
APENDICE 2. Estimativa do cus to horārio das máquinas e equipamentos agricolas utilizados na cultura de trigo e soja e' do custo diārio dos animais de trabalho e equipamentos utilizados na cultura de algodão

A metodologia adotada ē a mesma da publicação do Ministērio da Agricultura e Pecuária (Guia na seleção de máquinas e equipamentos agrícolas) mencionada no rodapé do capítulo 4 (Custo do Capital).

Os preços das máquinas e equipamentos foram obtidos do Banco Central e corresponde a vo valor CIF de importação para o ano de 1982.

Para os bens de capital de origem nacional (animais de tra balho e equipamento dos mesmos) os preços foram obtidos das informações recolhidas pelos técnicos do Banco Nacional de fomento e corresponde ao ano de 1982.

0 custo/hora das máquinas e equipamentos agrīcolas foi estimado somando-se o custo fixo/hora e o custo variāvel/hora.

0 custo fixo incluiu juros sobre o investimento médio e a depreciação do bem de capital em questão ou seja:

Custo fixo/hora $=$ Juros/hơra + Depreciação/hora

0 valor dos juros/ha (jh) foi calculado pela fórmula: 


$$
j h=\frac{\left(\frac{V a+V f}{2}\right)}{I U} i
$$

onde:

$V a=$ Valor atual do bem de capital medido em US $\$$ CIF de importação $V f=$ Valor final ou residual do bem de capital medido como uma por centagem $(10 \%)$ do valor atual do mesmo

$i=$ Taxa social de retorno a capital

$I U=$ Intensidade de uso anual, em horas

A depreciação (Dh) foi calculada pelo método linear de depreciação usando-se a förmula:

$$
D h=\frac{\frac{V a-V f}{n}}{I U}
$$

onde:

$$
n=\text { anos de vida }
$$

0 custo variāvel inclui gastos com combustīvel, manutenção (ōleo, graxa, filtros, etc.) e reparos.

CUSTO HORARIO DE UM TRATOR DE 65 HP
A) Custo Fixo/hora
Juro/hora $=0,62$
Depreciação/hora $=1,00$
Sub-Total $(A)=1,62$ US $\$ / \mathrm{hs}$ 
B) Custos Variāveis

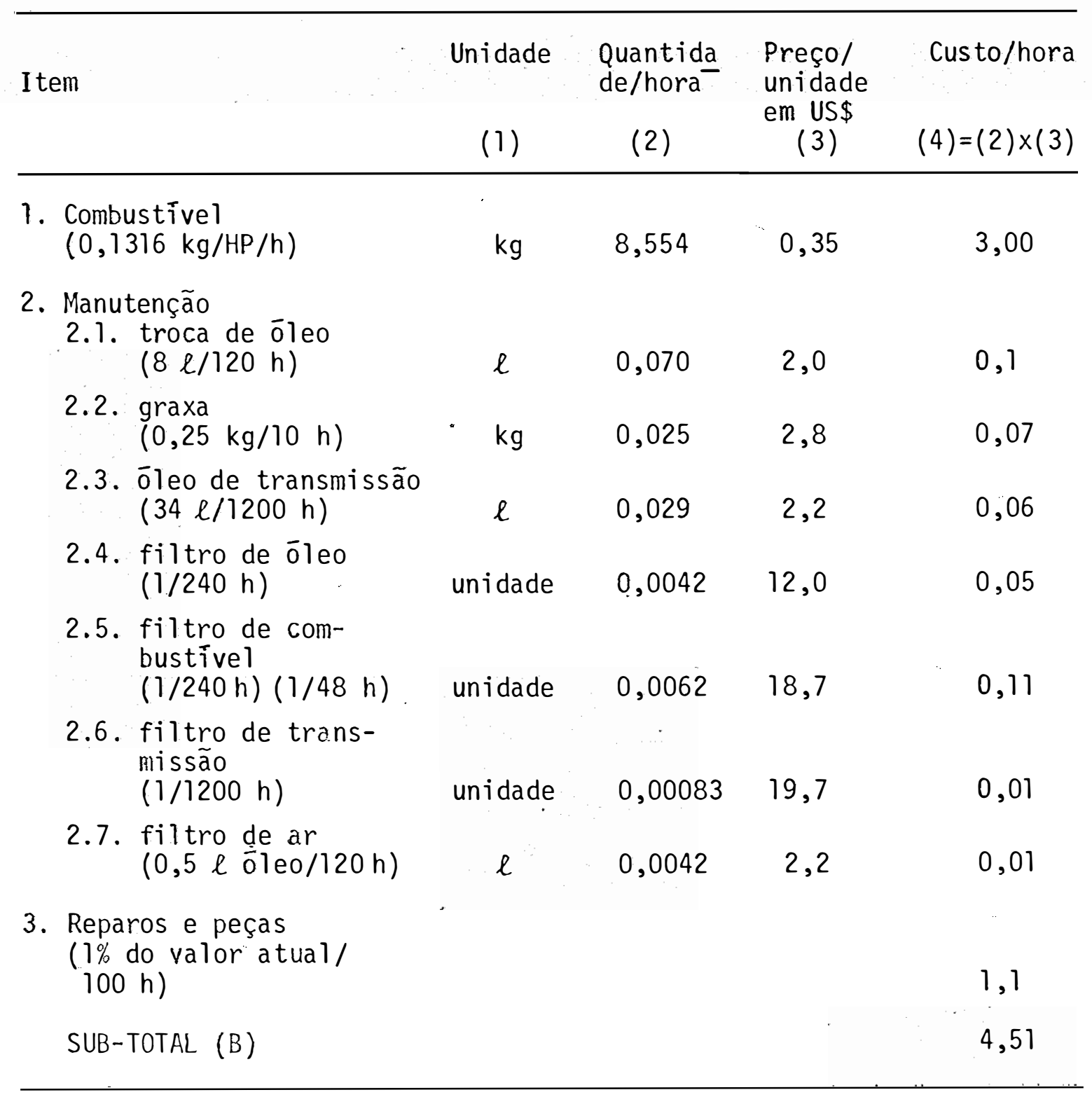

CUSTO HORARIO DE UMA COLHEDEIRA DE 97 HP

A) Custo Fixo/hora

Juro/hora $=3,5$

Depreciação/hora $=3,8$

$\operatorname{SUB}-\operatorname{TOTAL}(A)=7,3 \cup \mathrm{US} \$ / \mathrm{h}$ 
B) Custos Variāveis

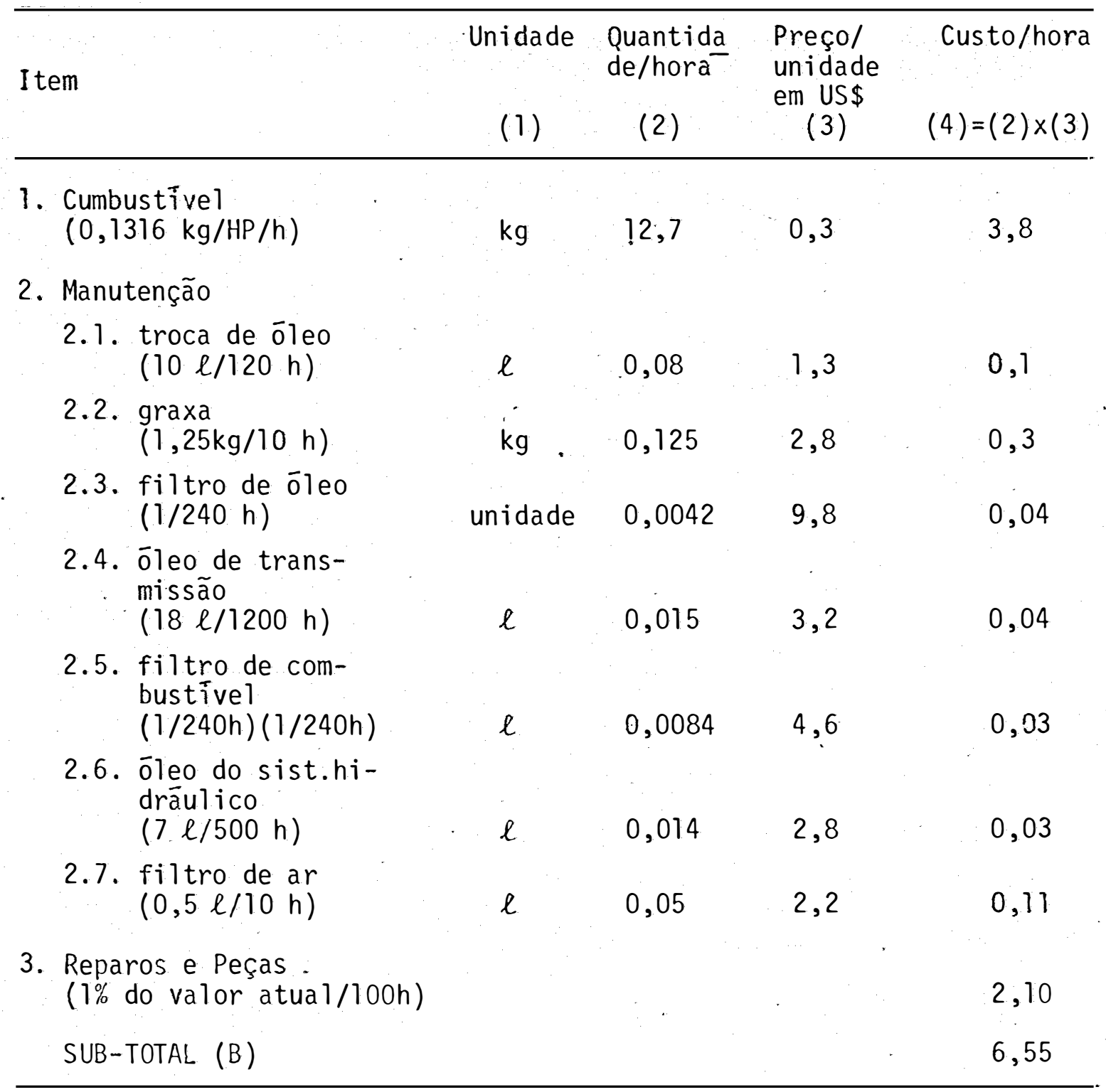

CUSTO HORARIO DE PULVERIZADOR PARA TRATOR EM US $\$ / \mathrm{h}$

Custo fixo/hora $=2,78$

Juro/hora $=1,33$

Depreciação/hora $=1,45$ 


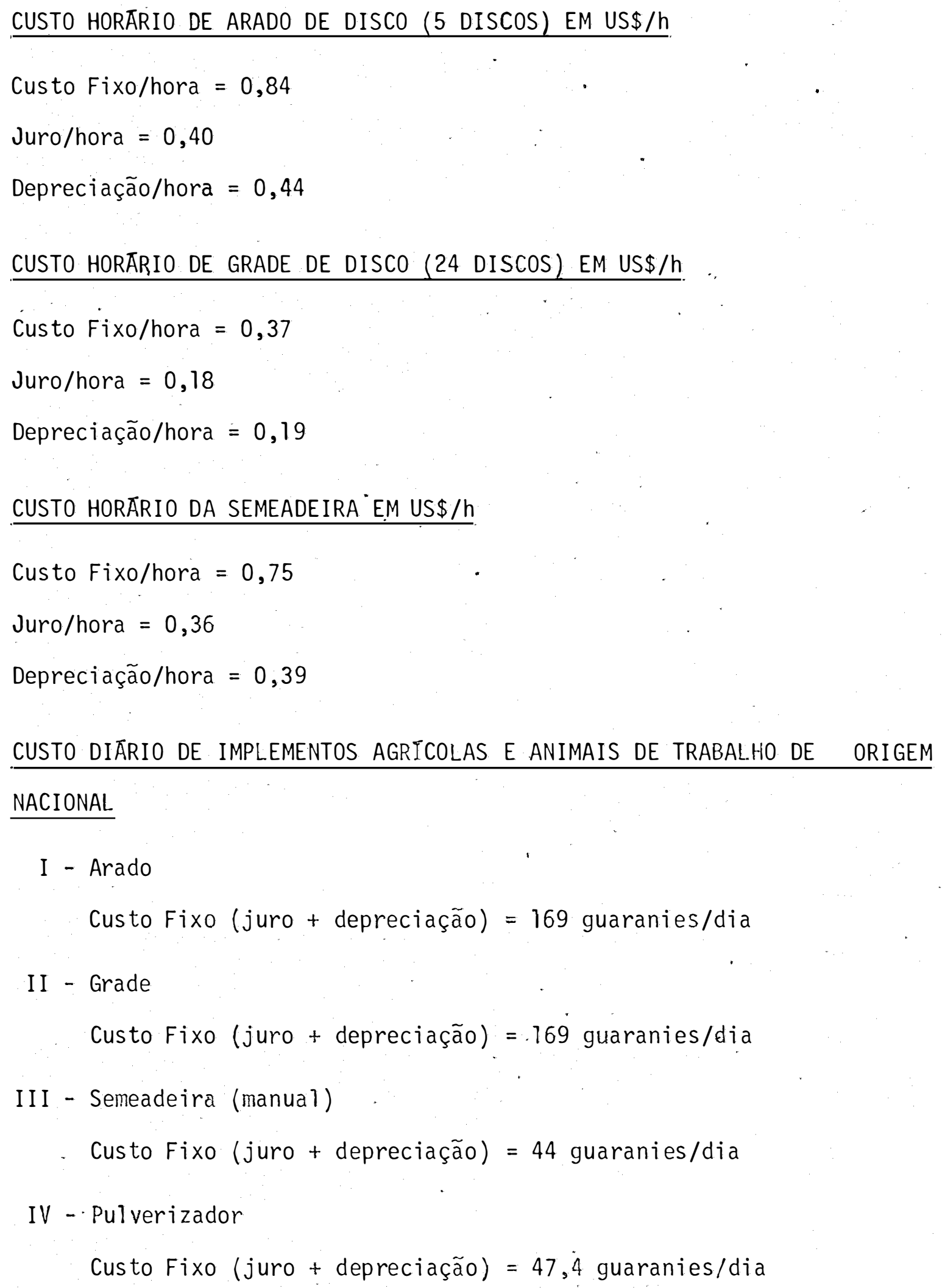


V - Animais de Trabalho

Custo Fixo (juro + depreciação) $=137$-guaranies $/$ dia

CUSTO TOTAL DE UTILIZAÇAO DE MAQUINARIA E IMPLEMENTOS AGRICOLAS, PARA 0

TRIG0 (em US\$ dōlares)

$\begin{array}{lc}\text { Horas de } & \text { Custo } \\ \text { uso por } & \text { horärio } \\ \text { hectare } & \text { (em US } \$ \text { ) }\end{array}$

Sub-total
US\$/
hectare

A - Custo Fixo

$A_{1}$. trator (65 HP)

6,5

1,62

10,53

$\mathrm{A}_{2}$. colhedeira $(97 \mathrm{HP}) \quad \cdot 1,0$

7,30

7,30

$A_{3}$. pulverização

1,0

2,78

2,78

$A_{4}$. arado de disco

2,5

0,84

2,10

$A_{5}$. grade de disco

2,0

0,37

0,74

$A_{6}$. semeadeira

1,0

0,75

0,75

SUB-TOTAL

B - Custos Variāveis

$B_{1}$. trator

- combustivivel

6,5

3,00

19,50

- manutenção

6,5

0,40

2, 60

- reparos e peças

6,5

1,10

7,20

$\mathrm{B}_{2}$. colhedeira

- combustível

1,0

3,80

3,80

- manutenção

1,0

0,65

3,80

- reparos e peças

1,0

2,10

2,10

SUB-TOTAL

CUSTO TOTAL $(A+B)=63,20$ dōlares $/$ ha 
CUSTO TOTAL DE UTILIZACCAO DE MAQUINARIA E IMPLEMENTOS AGRICOLAS PARA A SOJA (em US\$ dólares)

$\begin{array}{lcc}\text { Horas de } & \text { Custo } & \text { Sub-total } \\ \text { uso por } & \text { horārio } & \text { US\$/ } \\ \text { hectare } & \text { (em US\$) } & \text { hectare }\end{array}$

A - Custo Fixo

$A_{1} \cdot \operatorname{trator}(65 \mathrm{HP}$ )

$A_{2}$. colhedeira (97 HP)

$A_{3}$. pulverizador 1

$A_{4}$. arado de disco 3

$A_{5}$. gráde de disco 2

$A_{6}$. semeadeira

1

1,62

11,34

7,30

7,30

2,78

2,78

0,84

2,52

0,37

0,74

0,75

0,75

SUB-TOTAL

25,43

B - Custos Variāveis

$B_{j}$. trator

- combustivel

7

3,00

21,00

- manutenção

7

0,40

2,80

- reparos e peças

7

1,10

7,70

$\mathrm{B}_{2}$. colhedeira

- combustivel

3,80

3,80

- manutenção

0,65

0,65

- reparos e peças

2,10

2,10

SUB-TOTAL

38,05

CUSTO TOTAL $(A+B)=63,48$ US $\$ /$ hectare 
CUSTO TOTAL DE UTILIZAÇAOO DE ANIMAIS DE TRABALHO E IMPLEMENTOS AGRICOLAS NO PLANTIO DE ALGODAO

$$
\text { Dia/hectare } \begin{array}{cc}
\text { Custo/dia } & \text { Sub-total } \\
\text { (em guaranies) } & \text { guanies/ha }
\end{array}
$$

1 - Arado

3

169,0

507

2 - Grade

2

169,0

338

3 - Semeadeira

3

44,0

132

4 - Pulverizador

8

5

47,4

379

5 - Animais de trabalho

137,0

685

TOTAL 
APENDICE 3. Custo de Produção de um hectare de Trigo, Soja, Algodão e Fumo

0 custo de produção apresentado no presente apēndice, foi utilizado na estimativa da taxa de câmbio implícita (dj). Os va- lores contidos nas tabelas correspondem a valores de eficiência e de mercado. 
Custo de Produção de um hectare de Trigo (produção 1,2 t) a Preços de Mercado e de Eficiēncia, Paraguai, Ano Agrícola 1982/83

\begin{tabular}{lcc}
\hline Recurso & $\begin{array}{c}\text { Custo a Preço } \\
\text { de Mercado } \\
\text { (por hectare) }\end{array}$ & $\begin{array}{c}\text { Custo a Preço de } \\
\text { Eficiência }\end{array}$ \\
\hline $\begin{array}{c}\text { (por } \\
\text { hectare) }\end{array}$ (por to- \\
nelada)
\end{tabular}

A. Domésticos $\frac{a /}{\text { : }}$

- terra

$15.750,0 \quad 13.125,0$

- mão-de-obra

$5.000,0$

$2.145,0$

$1.787,0$

- capital

$7.175,0$

$5.979,0$

- semente

$7.000,0$

$7.000,0$

$5.833,0$

SUB-TOTAL

$28.800,0$

$32.070,0$

$26.724,0$

B. Importados- - :

- fertilizantes e defensivos

$24.678,4$

$24.678,4$

$20.565,3$

- māquinas e equipamentos

$15.231,2$

$15.231,2$

$12.692,6$

- transporte

$-$

$\quad 3.615,0$

SUB-TOTAL

$39.909,6$

$39.909,6$

$36.879,9$

a/ em guaranies; obtido do Serviço de Extensão Agrīcola, Paraguai

b/ em guaranies; transformado pela taxa de cámbio de equilíbrio 
Custo de Produção de um hectare de Soja (produção 1,6 t) a Preços de Mercado e de Eficiência, Paraguai, Ano Agrĩcola 1982/83

\begin{tabular}{lcc}
\hline Recurso & $\begin{array}{c}\text { Custo a Preço } \\
\text { de Mercado } \\
\text { (por hectare) }\end{array}$ & $\begin{array}{c}\text { Custo a Preço de } \\
\text { Eficiencia }\end{array}$ \\
\cline { 3 - 4 } & $\begin{array}{c}\text { (por } \\
\text { hectare) }\end{array}$ & $\begin{array}{c}\text { (por to- } \\
\text { nelada) }\end{array}$ \\
\hline
\end{tabular}

A. Domésticosal:

$\begin{array}{lccr}\text { - terra } & & 15.750,00 & 9.843,00 \\ \text { - mão-de-obra } & 4.600,00^{\circ} & 1.973,00 & 1.234,00 \\ \text { - capital } & - & 4.473,00 & 2.795,00 \\ \text { - semente } & 3.900,00 & 3.900,00 & 2.437,00 \\ & & & \\ \text { SUB-TOTAL } & 25.300,00 & 26.096,00 & 16.309,00\end{array}$

B. Importados-

- fertilizantes e defensivos

$13.544,20 \quad 13.544,20 \quad 8.465,13$

- máquinas e equipamentos

$15.298,68 \cdots \quad 15.298,68 \quad 9.561,68$

- transporte

$-$

$-\quad 4.795,90$

SUB-TOTAL

$28.842,88$

$28.842,88 \cdot 22.822,71$

a/ em guaranies; obtido do Serviço de Extensão Agrícola, Paraguai

b/ em guaranies; transformado pela taxa de câmbio de equilíbrio 
Custo de Produção de um hectare de Algodão (produção 0,834 t) a Preços de Mercado e de Eficiência, Paraguai, Ano Ağrīcola 1982/83

\begin{tabular}{|c|c|c|c|}
\hline \multirow{2}{*}{ Recurso } & \multirow{2}{*}{$\begin{array}{l}\text { Custo a Preço } \\
\text { de Mercado } \\
\text { (por hectare) }\end{array}$} & \multicolumn{2}{|c|}{$\begin{array}{c}\text { Custo a Preço de } \\
\text { Eficiencia }\end{array}$} \\
\hline & & $\begin{array}{l}\text { (por } \\
\text { hectare) }\end{array}$ & $\begin{array}{l}\text { (por to- } \\
\text { nelada) }\end{array}$ \\
\hline
\end{tabular}

A. Domésticos $=$ /:

$\begin{array}{lcrr}\text { - terra } & & 17.250,00 & 20.683,00 \\ \text { - mão-de-obra } & 32.500,00 & 13.942,00 & 16.718,00 \\ \text { - capital } & - & 7.569,00 & 9.075,00 \\ \text { - semente } & 1.950,00 & 1.950,00 & 2.338,00 \\ & & & \\ \text { SUB-TOTAL } & 52.850,00 & 40.711,00 & 48.814,00\end{array}$

B. Importados $\underline{\text { b/ }}$ :

- defensivos

$11.568,00$

$11.568,00 \quad 13.870,50$

- transporte.

-..

$-\quad 2.289,50$

SUB-TOTAL

$11.568,00$

$11.568,00 \quad 16.160,00$

a/ em guaranies; obtido do Serviço de Extensão Agrícola, Paraguai

b/ em guaranies; transformado pela taxa de câmbio de equilibrio 
Custo de Produção de um hectare de Fumo (produção 1,4 t) a Preços de Mercado e de Eficiência, Paraguai, Ano Agrícọla 1982/83

\begin{tabular}{ccc}
$\begin{array}{c}\text { Custo a Preço } \\
\text { de Mercado } \\
\text { (por hectare) }\end{array}$ & $\begin{array}{c}\text { Custo a Preço de } \\
\text { Eficiência }\end{array}$ \\
\cline { 3 - 4 } & $\begin{array}{c}\text { (por } \\
\text { hectare) }\end{array}$ & $\begin{array}{c}\text { (por to- } \\
\text { nelada) }\end{array}$ \\
\hline
\end{tabular}

A. Domésticos $\underline{\text { a/ }}$ :

- terra

- mão-de-obra

- capital

- semente

SUB-TOTAL

$\begin{array}{rrr} & 13.500,00 & 9.643,00 \\ 99.450,00 & 42.664,00 & 30.474,00 \\ - & 18.405,00 & 13.146,00 \\ 500,00 & 500,00 & 357,00 \\ 0 & & \\ 114.350,00 & 75.069,00 & 53.620,00\end{array}$

B. Importados $\underline{\text { b/ }}$ :

- defensivos

$11.327,00$

$11.327,00$

$8.090,70$

- material para sementeira

$9.326,70$

$9.326,70$

$6.661,93$

- transporte

$-$

\begin{tabular}{l}
$-\quad 2.410,00$ \\
\hline
\end{tabular}

SUB-TOTAL

$20.653,70$

$20.653^{\prime}, 70$

$17.162,63$

a/ em guaranies; obtido do Serviço de Extensão Agrīcola; Paraguai

b/ em guaranies; transformado pela taxa de cãmbio de equilíbrio 